NBER WORKING PAPER SERIES

GOVERNMENT DEBT AND BANKING FRAGILITY:
THE SPREADING OF STRATEGIC UNCERTAINTY

\author{
Russell Cooper \\ Kalin Nikolov \\ Working Paper 19278 \\ http://www.nber.org/papers/w19278 \\ NATIONAL BUREAU OF ECONOMIC RESEARCH \\ 1050 Massachusetts Avenue \\ Cambridge, MA 02138 \\ August 2013, Revised September 2017
}

We are grateful to seminar participants at the Federal Reserve Bank of Kansas City, the CornellPSU Fall 2013 meeting, McGill University, the International Macroeconomics Conference at the Federal Reserve Bank of Atlanta, the University of Pittsburgh, the Riksbank and the Guanghua School of Management at Peking University for helpful comments and questions. The views expressed herein are those of the authors and do not necessarily reflect the views of the National Bureau of Economic Research.

NBER working papers are circulated for discussion and comment purposes. They have not been peer-reviewed or been subject to the review by the NBER Board of Directors that accompanies official NBER publications.

(C) 2013 by Russell Cooper and Kalin Nikolov. All rights reserved. Short sections of text, not to exceed two paragraphs, may be quoted without explicit permission provided that full credit, including $(\odot$ notice, is given to the source. 
Government Debt and Banking Fragility: The Spreading of Strategic Uncertainty

Russell Cooper and Kalin Nikolov

NBER Working Paper No. 19278

August 2013, Revised September 2017

JEL No. E44,G33,H12,H63

\begin{abstract}
This paper studies the interaction of government debt and financial markets. Both markets are fragile: excessively responsive to fundamentals and prone to strategic uncertainty. This interaction, termed a 'diabolic loop', is driven by government choice to bail out banks and the resulting incentives for banks to hold government debt rather than to self-insure through equity buffers. We provide conditions such that the 'diabolic loop' is a Nash Equilibrium of the interaction between banks and the government. Instability originates in debt markets and is channeled to financial arrangements, and then back again.
\end{abstract}

The analysis highlights the critical role of bank equity for the existence of a diabolic loop. When equity is issued, no diabolic loop exists. In equilibrium, banks' rational expectations of a bailout ensure that no equity is issued and the sovereign-bank loop operates.

\author{
Russell Cooper \\ Department of Economics \\ The Pennsylvania State University \\ 611 Kern \\ State College, PA 16802 \\ and NBER \\ russellcoop@gmail.com \\ Kalin Nikolov \\ European Central Bank \\ Financial Research Department \\ Kaiserstrasse 29 \\ Frankfurt-am-main \\ Germany \\ Kalin.Nikolov@ecb.int
}




\title{
Government Debt and Banking Fragility: The Spreading of Strategic Uncertainty*
}

\author{
Russell Cooper ${ }^{\dagger} \quad$ Kalin Nikolov ${ }^{\ddagger}$ \\ This Version: May 2, 2017 \\ First Version: August 9, 2013
}

\begin{abstract}
This paper studies the interaction of government debt and financial markets. Both markets are fragile: excessively responsive to fundamentals and prone to strategic uncertainty. This interaction, termed a 'diabolic loop', is driven by government choice to bail out banks and the resulting incentives for banks to hold government debt rather than to self-insure through equity buffers. We provide conditions such that the 'diabolic loop' is a Nash Equilibrium of the interaction between banks and the government. Instability originates in debt markets and is channeled to financial arrangements, and then back again.

The analysis highlights the critical role of bank equity for the existence of a diabolic loop. When equity is issued, no diabolic loop exists. In equilibrium, banks' rational expectations of a bailout ensure that no equity is issued and the sovereign-bank loop operates.
\end{abstract}

\section{Introduction}

The following quote is from a 2012 speech by IMF Director Christine Lagarde:

We must also break the vicious cycle of banks hurting sovereigns and sovereigns hurting banks. This works both ways. Making banks stronger, including by restoring adequate capital levels, stops banks from hurting sovereigns through higher debt or contingent

\footnotetext{
*We are grateful to seminar participants at the Federal Reserve Bank of Kansas City, the Cornell-PSU Fall 2013 meeting, McGill University, the International Macroeconomics Conference at the Federal Reserve Bank of Atlanta, the University of Pittsburgh, the Riksbank and the Guanghua School of Management at Peking University for helpful comments and questions.

${ }^{\dagger}$ Department of Economics, Pennsylvania State University, USA, email: russellcoop@gmail.com

${ }_{\ddagger}^{\ddagger}$ Research Department, European Central Bank, Kaiserstrasse 29, Frankfurt-am-Main, email: kalin.nikolov@ecb.int
} 
liabilities. And restoring confidence in sovereign debt helps banks, which are important holders of such debt and typically benefit from explicit or implicit guarantees from sovereigns ${ }^{1}$

Following the Greek sovereign debt write-down in 2011, the four largest Greek banks made losses of more than 28 billion euros (or $13 \%$ of GDP) ${ }^{2}$ This was enough to wipe out almost all of their combined equity capital. In 2010, the Irish government ran an unprecedented peace-time deficit, reaching $32 \%$ of GDP as it bailed out its banking system. Under the weight of nationalized banks' losses, Ireland was forced to seek financial support from the IMF and the EU in November 2010.

These are two recent examples of a 'diabolic loop' between banks and sovereigns. In the case of Greece, banks that were otherwise solvent, were made insolvent by the default of their sovereign whose debt they were holding ? $^{3}$ In the case of Ireland, a government which had previously had one of the lowest levels of debt to GDP in Europe, suffered a withdrawal of funding as markets became concerned about the contingent liabilities involved in bailing out its large, insolvent banking system.

Throughout the rest of southern Europe (most notably Italy and Spain), this 'diabolic loop' did not lead to outright sovereign default but nevertheless contributed to strains in sovereign and bank debt markets due to beliefs that government default was increasingly likely. As outright default is infrequent, the interaction we highlight in our analysis is between beliefs about default and the functioning of the intermediation process, as in these countries. This is consistent with the emphasis on "confidence" and thus beliefs about default in the quote of Christine Lagarde.

Importantly, these episodes make clear that bailouts of domestic banks by national governments do not tend to offset instability of debt markets but rather contribute to it. This is made explicit in our model as sovereign debt fragility arises due to a strategic complementarity between the buyers of government bonds, operating through government default, as in Calvo (1988). Since the government's ability to repay debt depends inversely on the real interest rate it has to pay, this opens up the possibility of self-fulfilling pessimistic equilibria in which the high interest rate needed to compensate bond holders for high expected default risk weakens the government's solvency and validates the pessimistic default expectations.

The analysis identifies two sources of fragility in debt markets. First, suppose, as was the case in Ireland, the government is expected to bailout troubled banks by issuing additional debt. In this case, pessimism about government default hurts banks balance sheets and thus induces the government to choose to bail banks out in order to prevent them from collapsing even though this choice comes at the cost of a higher risk of sovereign default. This is the 'diabolic loop' in its purest form - the government's bailout decision saves the banks from the immediate consequences

\footnotetext{
${ }^{1}$ This entire speech by Christine Lagarde, Managing Director, IMF, is available at https://www.imf.org/ external/np/speeches/2012/012312.htm

${ }^{2}$ National Bank of Greece, Alpha Bank, Pireus and Eurobank.

${ }^{3}$ The term 'diabolic loop' was evidently coined by Markus Brunnermeier in a presentation on the Euro Crisis at the July 2012 NBER Summer Institute.
} 
of pessimism but also validates the initial pessimism itself.

We also stress a second factor that creates multiplicity in sovereign debt valuations. Governments undertake public expenditures some of which are financed by issuing new debt. When the government has a fixed level of fiscal expenditure, the amount of debt needed to finance this expenditure is endogenous. If default is viewed to be more likely, the subsequent decline in debt prices implies that the government will need to sell more debt to finance a fixed level of expenditure, thus validating the expectations.

These two sources of multiplicity in debt markets are different in terms of both origins and implications. The first reflects beliefs about government bailout and is easily remedied by a credible promise not to support the banks. The second is more fundamental to the conduct of fiscal policy and thus remains even if under a no bailout commitment. Both are relevant for understanding the experiences of individual countries, such as Ireland and Greece.

The key questions we ask is why banks and governments act so as to deepen the sovereign-bank linkages that activate the 'diabolic loop'. There is a strong tendency by banks to hold (their own) government debt without capital buffers to protect them against this exposure. Governments then usually bail banks out when they get into solvency problems. Both of these links are the result of optimizing choices by banks and governments within our model. We show that, in the equilibrium with government bailout, banks have no incentive to issue equity. And if banks are exposed to sovereign debt and have no buffers, governments find it too costly ex post not to step in and provide assistance when the price of sovereign debt falls. The 'diabolic loop' is therefore a subgame perfect Nash equilibrium.

Battistini, Pagano, and Simonelli (2014) provide compelling evidence for rent seeking behaviour by banks in anticipation of bailouts. They show that southern european banks increased their holdings of domestic sovereign debt in response to an increase in country-specific risk - a finding they attribute to moral hazard.4

Given the instability of debt markets, how are households insured? Answering this question is the focus of the policy analysis in the paper. The insurance may arise through the banking system, where the risk is borne by risk neutral equity investors who absorb any losses on bank government bond holdings. Or the insurance may arise through a government bailout of the banks, financed by government borrowing. We show that the two modes of providing insurance deliver the same utility to risk averse households but at very different social cost. While insuring through equity is costless and avoids debt fragility, bailouts are the reason for debt fragility and bring deadweight default losses to the extent that they lead to a positive probability of government insolvency.

To be clear, there are actions by banks and governments to break this vicious circle. On the banking side, equity cushions can break the adverse feedback between banks and sovereigns. Banks

\footnotetext{
${ }^{4}$ Yet another possibility is 'moral suasion' by domestic governments who put pressure on their banks to buy domestic sovereign debt. Ongena, Popov, and Van Horen (2015) find evidence for this during the Euro Area debt crisis.
} 
that hold adequate capital against potential sovereign risks can absorb losses from government default thus becoming completely insulated from developments in debt markets. However, when banks expect bailout assistance to be provided ex post, the incentive for them to self-insure by building up equity buffers against losses disappears. In this way, the analysis contains an important moral hazard problem: the incentive for banks to hold government debt without equity buffers is impacted by an anticipated bailout choice of the government.

On the sovereign side, if the resolution of a collapsed financial system is not very costly, then governments will choose not to provide a bailout in our model, thus severing the diabolic loop. Further, a sovereign with the power to commit ex ante would choose not to do so, leaving it to the banks to protect depositors through equity buffers.

The paper lends support to regulatory interventions which strengthen capital requirements. Further, policies that provide incentives for banks to hold domestic debt, such as the zero risk weight in the Basel III regime, only strengthen the 'diabolic loop'. Interventions to increase capital requirements and reduce bank reliance on domestic debt holdings would weaken the 'diabolic loop', consistent with the policy goals of IMF Director Christine Lagarde.

Related Literature The interaction between sovereign and bank balance sheets has been the subject of a growing literature. There are both empirical and theoretical contributions related to our work.

There is ample evidence for the interaction we study in the paper. Acharya, Drechsler, and Schnabl (2014) and Hannoun (2011) show that European sovereign and bank CDS prices exhibit positive co-movement over the crisis period while showing little correlation pre-crisis. When government and bank balance sheets become closely intertwined, their default probabilities become highly correlated too. Our focus on bailouts as an important linkage between banks and sovereigns is supported by Pagano (2014) who provides evidence that European governments have shown a greater willingness to provide assistance to financial institutions compared to the US and UK.5

Acharya, Drechsler, and Schnabl (2014) also model the balance sheet linkages between banks and sovereigns but take banks' sovereign debt holdings as given while Livshits and Schoors (2012) examine the incentives of banks to overinvest in risk government debt. Neither of the two considers how anticipated bailouts affect banks' incentives to invest in government bonds and/or issue equity to guard against sovereign exposures ${ }^{6}$

In an independent but closely related paper, Farhi and Tirole (2014) examine the effects of fun-

\footnotetext{
${ }^{5}$ Pagano (2014) examines the difference in banks' 'standalone' credit ratings with the ratings they receive when potential government support is taken into account. He shows that government support reduces banks' funding costs by 60 bps in the EU as compared to 10-20 bps for the US and UK.

${ }^{6}$ Bolton and Jeanne (2011) consider international spillovers through cross-country sovereign debt holdings. Lucas, Schwaab, and Zhang (2014) present evidence for such cross-country spillovers. Lucas, Schwaab, and Zhang (2017) examines the macroeconomic effects of higher sovereign default risk in a quantitative macro model of the Italian economy.
} 
damental shocks in creating feedback effects between banks and sovereigns. Their paper constructs a model in which, again, banks overinvest in sovereign debt and governments find it optimal to bail them out ex post, activating the loop. Farhi and Tirole (2014) focus on explaining why domestic banks do not diversify their government bond portfolios instead choosing to hold domestic bonds even when risks are high. In contrast, our paper emphasizes strongly the role of bank equity as a mechanism to avoid the sovereign-bank loop. In our framework, banks' weak incentives to issue equity against sovereign exposures is a key reason why the loop exists in the first place. Further, our analysis stresses the significance of beliefs about default.

Uhlig (2013) appeals to moral hazard in order to explain banks' tendency to hold large quantities of government debt. In Uhlig (2013), inadequate collateral haircuts imposed by the central bank in a monetary union allow weak country banks to profitably default on the central bank when economic fundamentals deteriorate. Leonello (2014) analyses strategic complementarities between bank depositors and sovereign debt holders and uses a 'global games' framework to endogenize the crisis probability.

Gennaioli, Martin, and Rossi (2013) offer a more positive view of banks' government debt holdings. They show that banks' domestic debt exposures can serve as a government commitment device against strategic sovereign default. Defaulting on debt held by banks causes large credit contractions so when selective default is impossible, this increases the amount of debt the government can credibly promise to repay.

Our paper differs in two important respects from theirs. First, our focus on multiple equilibria shifts the emphasis on to beliefs about default rather than the occurrence of default itself. In our model, movements in the price of government debt damage bank balance sheets long before payments on government debt become due. Then a government which would like to safeguard financial intermediation only has bailouts at its disposal in order to do so. This is the second key departure of our paper from Gennaioli, Martin, and Rossi (2013). In their model, a bailout is exogenous and has no implications for the value of government debt. In ours, the bailout of the banking system is endogenous and has a direct influence on the value of government debt. It is key to establishing the two-way linkages between banks and sovereigns: if the government chooses to bailout the banks, then its debt burden and its cost of borrowing rise making future default more likely.

Broner, Erce, Martin, and Ventura (2014) show using a different mechanism, that banks' holdings of government debt can become a source of multiple equilibria in the sovereign debt market by crowding out lending for productive purposes during fiscal crises.$^{7}$ Our mechanism for generating multiplicity is complementary to theirs and relies on the feedback between government bailouts of banks and the probability of sovereign default.

Our analysis differs from these other studies in a number of ways. First, our paper places

\footnotetext{
${ }^{7}$ Gennaioli, Martin, and Rossi (2014) and Popov and Van Horen (2015) provide empirical evidence of such effects in the european sovereign debt crisis.
} 
strategic complementarities and multiple equilibria at the heart of the analysis $\sqrt[8]{ }$ For us, beliefs about default are critical as they drive debt prices and, in turn, bank solvency. The diabolic loop is instrumental here in two dimensions. The link from the debt market to banks can amplify the effects of strategic uncertainty associated with the valuation of government liabilities. Further, a credible promise to support the banks can by itself become the source of multiplicity.

Second, our analysis highlights the role of banks' equity buffers for the existence and severity of the 'diabolic loop'. As we show subsequently, significant investments in government bonds are not a problem per se as long as banks hold significant capital buffers against sovereign exposures. But, anticipating a bailout, banks will not have an incentive to create this equity buffer. In this respect our paper is also related to the work of Admati and Hellwig (2013) which stresses the importance of adequate equity buffers in order to make banking safe without resorting to bailouts.

Finally, our analysis ties the bank and debt fragility together through the process of dealing with failed banks. If the breakdown of the intermediation process, mediated through an optimal resolution mechanism, is not too costly, then the government's will not have a big incentive to support the banking system. This leaves depositors vulnerable to any banking instability, leading to self-insurance via equity buffers. In this case, paradoxically, the probability of government default is lower since the banks are not supported 9 Further, for some specifications of the model, the diabolic loop does not exist when the sovereign does not bailout the banks.

\section{Framework}

Time lasts for three periods: 0, 1 and 2. The model has two principal components. The first is a banking relationship between intermediaries and depositors, following Diamond and Dybvig (1983). The second component is the pricing of government debt, following Calvo (1988) and others.$^{10}$

The intermediation process and pricing of government debt are linked in a couple of ways. First, the value of the government debt held by the banks affects their solvency. Second, the potential and realized needs to bailout the financial sector influences the value of government debt. These interactions can be activated by either fundamental shocks or self-fulfilling expectations influencing the value of government debt.

The diabolic loop appears in the middle period. This is the stage where beliefs about the

\footnotetext{
${ }^{8}$ Yet another approach to analyzing strategic complementarities would be to use the global games approach of Carlsson and Van Damme (1993) and Morris and Shin (1998) to obtain uniqueness and replace a response to sunspots with amplification of fundamental shocks. As, for example, Vives (2014) has argued in the context of a banking fragility problem, uniqueness actually obtains under very restrictive assumptions on the interplay of private and public signals. See De Grauwe and Ji (2012) for a discussion of empirical evidence.

${ }^{9}$ This contrasts with Gennaioli, Martin, and Rossi (2013). In their setting, a costly bank resolution mechanism is an important commitment device to limit default.

${ }^{10}$ There are now a number of papers building on Calvo (1988), including Cole and Kehoe (2000) and, more recently, Corsetti and Dedola (2012), Roch and Uhlig (2012), Cooper (2012) and many others.
} 
prospect of government default in the last period influences the value of government debt and thus the operation of the banks. Further, it is in this middle period that the government decides to bailout the banks or not. While the ultimate repayment of debt in the last period matters for its value in period 1 , the actual default decision is not very important to our results. That is, the interactions we highlight are not about the effects of default on the banking system but rather reflect the power of beliefs about future default on the operation of banks and the bailout choice of a government.

There are four types of agents: households, banks, investors and the government. We discuss the choices and objectives of these agents and then characterize the equilibria.

Ultimately the uncertainty in the model will come from self-fulfilling variations in investors beliefs about government debt repayment. That is, we will study debt fragility as part of a sunspot equilibrium. In framing the choice problems for agents, let $s$ denote the state of the economy. The state is linked to investor beliefs in the characterization of a sunspot equilibrium in section 4.

Two choice problems are key to the construction of the sunspot equilibria. First, the contracting problem with the households includes a critical choice of the banks about how much government debt to hold and whether to issue equity in order to buffer depositors against fluctuations in the value of sovereign debt. A government bailout that protects banks without equity buffers against a pessimism-induced decline in the market value of sovereign debt impacts the above two decisions. Second, in the event of pessimism, the government chooses whether or not to bailout otherwise insolvent banks.

\subsection{Households}

Households are of size 1 . They have an endowment of goods $d$ at $t=0$ with preferences

$$
V_{0}^{H}=\pi u\left(c_{1}+\beta c_{2}\right)+(1-\pi) u\left(\beta c_{1}+c_{2}\right)
$$

where $\beta$ is less than 1 . With probability $\pi$ they are early consumers who prefer consuming at $t=1$ and with probability $1-\pi$ they are late consumers who prefer consuming at $t=2$. The shares of early consumers at the aggregate level is fixed at $\pi$. We assume $u(\cdot)$ is strictly increasing, strictly concave and $u(0)$ is finite.

\subsection{Banks}

Following Diamond and Dybvig (1983), consumers can share liquidity risk through the banking system. As in that framework, household types are private information.11

Banks construct a portfolio for households which provides the needed liquidity while still taking advantage of longer term investment opportunities. In addition to providing liquidity, the bank

\footnotetext{
${ }^{11}$ Since our focus is on strategic uncertainty emanating from debt markets, the role of the private information in generating bank runs is not key to the analysis.
} 
provides insurance to households, both against their individual taste shock and government default risk. As is well understood, it is this interaction of liquidity needs and illiquid investment that can lead to fragility in the banking system. In our framework, by holding government debt as a means of meeting the liquidity needs of households, the bank is exposed to fluctuations in the value of government debt.

Banks are competitive. Ex ante, banks offer contracts to consumers. The contract specifies the levels of early, denoted $c^{E}(s)$, and late consumption, denoted $c^{L}\left(s, \mathbb{1}_{G}\right)$, dependent on the sunspot state $s$, realized in period 1 , as well as the period 2 government repayment decision, where $\mathbb{1}_{G}=1$ if the government defaults on its debt and $\mathbb{1}_{G}=0$ if there is repayment. They raise deposits $d$ from households in period 0 . Investors also supply equity, denoted $x_{0}$, to the bank.

Banks invest in two types of assets in period 0 . They can buy government bonds $b_{0}$ at price $q_{0}$. These bonds do not pay a coupon at the middle date but can be traded in the secondary market. Second, banks can make long term investments $i_{0}$ that return $R>1.12$

These investments have a liquidation value at the middle date of $0 \leq \varepsilon \leq 1$. Banks can adjust their portfolios in the middle period, after $s$ is realized.

The optimal contract between the banks and the households solves:

$$
\max _{i_{0}, b_{0}, x_{0}, c^{E}(s), c^{L}\left(s, \mathbb{1}_{G}\right), \delta_{2}\left(s, \mathbb{1}_{G}\right), l_{1}(s), b_{1}(s), L_{1}(s)} E\left[\pi u\left(c^{E}(s)\right)+(1-\pi) u\left(c^{L}\left(s, \mathbb{1}_{G}\right)\right)\right]
$$

such that

$$
\begin{gathered}
i_{0}+q_{0} b_{0} \leq d+x_{0} \\
\pi c^{E}(s) \leq q_{1}(s)\left(b_{0}-b_{1}(s)\right)+\varepsilon l_{1}(s)+L_{1}(s)+T\left(q_{1}(s), b_{0}\right) \forall s \\
(1-\pi) c^{L}\left(s, \mathbb{1}_{G}\right) \leq\left(1-\mathbb{1}_{G}\right) b_{1}(s)+R\left(i_{0}-l_{1}(s)\right)-\delta_{2}\left(s, \mathbb{1}_{G}\right)-r^{b}(s) L_{1}(s) \forall s \\
E \delta_{2}\left(s, \mathbb{1}_{G}\right) \geq R x_{0} . \\
E u\left(c^{L}\left(s, \mathbb{1}_{G}\right)\right) \geq u\left(\beta c^{E}(s)\right) ; E u\left(c^{E}(s)\right) \geq u\left(\beta c^{L}\left(s, \mathbb{1}_{G}\right)\right) \forall s
\end{gathered}
$$

In this problem, the expectation is taken over the distribution of the sunspot variable, $s$, and over the distribution of government default.

From (2), the total funding of the bank, $d+x_{0}$, is invested in illiquid investment, $i_{0}$ and government bonds, $b_{0}$, at a price $q_{0}$. The funding for the payment to the early households comes from three sources, as indicated by (3). First, the bank can sell some of the government debt it acquired in period 0 to the investors to obtain goods for early consumers. These sales occur at a state contingent price $q_{1}(s)$. Second, the bank could liquidate some of the illiquid investment, denoted $l_{1}(s)$ in (3). The liquidation of the illiquid technology is equivalent to having access to a storage

\footnotetext{
${ }^{12}$ An alternative source of liquidity for banks is for banks to lend to investors or other banks at the early date. We do not consider this alternative liquidity source in our analysis. If such a market did exist in the model, then in equilibrium, banks would be indifferent between using it and using bonds as liquidity. Hence, the fact that we ignore such a market is not a binding restriction on the set of assets banks have access to.
} 
technology with a return of $\varepsilon$ between period 0 and 1 . Third, the bank could borrow from investors or other banks, denoted $L_{1}(s)$ in (3), at a rate $r^{b}(s)$. We refer to this as a loan in the interbank market.

The bank may receive bailout transfers $T\left(q_{1}(s), b_{0}\right)$ from the government which depend on government debt prices as well as the bank's holding of government debt. The bailout transfer is treated as exogenous by individual banks but it is fully taken into account in their optimal portfolio allocation. It will play an important role in subsequent analysis and its value will derive from optimizing decisions by the government which will be explained in detail in due course. The above sources of funds allow the bank to finance $c^{E}(s)$.

Fourth, the contract is subject to the usual incentive compatibility constraints (6) that state that the contract allocations must be such that consumers prefer their own allocation rather than the allocation of the other type. Here the allocation of late consumers is, in principle, subject to uncertainty due to the possibility that the government defaults on bonds held to maturity by the bank. This is why we have the expectations operator in (6) - it is taken with respect to the distribution of sovereign default at the final date.

Importantly, banks are not being forced to hold government debt. They can meet liquidity needs in period 1 by borrowing from investors or other banks. As we shall see, this choice between the holding of government debt and utilizing the interbank market is determined in equilibrium and influenced by both the uncertainty over the pricing of government debt and the bailout decision of the government.

From (4), the state contingent consumption of late households is financed by the bonds held until the last period as well as the return on the illiquid investment that was not liquidated in the middle period. Further, the bank has the returns to investor loans made at the middle date.

The penultimate constraint, (5) ensures that the expected return on equity is not less than the outside option of investing $x_{0}$ in the illiquid technology. Here $\delta\left(s, \mathbb{1}_{G}\right)$ is the state contingent payout of dividends to equity holders. The nature of this contingency and thus how the investors provide insurance to depositors is part of the equilibrium construction.

The potential risks to depositors should be clear from this optimization problem. First, there is uncertainty over the period 1 value of government debt. Second, there is sovereign default risk. The optimal contract will optimally allocate this risk between households and investors as well as provide liquidity to early households.

The first-order conditions for this problem are analyzed in Section 9.1 in the Appendix. These conditions are used to characterize the equilibria in Section 4 . The choice of the government of the transfer function, $T\left(q_{1}(s), b_{0}\right)$, is presented in Section 2.4.3.

In the construction of equilibria, it will be necessary to describe the outcome of the banking arrangement when banks anticipate government support but, off the equilibrium path, it chooses not to provide it. Under such an eventuality, the bank is insolvent and must be 'resolved'. We will delay a full discussion of the 'resolution mechanism' until the characterization of equilibria. 
For now, it is important to stress that the resolution procedure we assume is costly in the sense that a fraction $\psi$ of bank assets are lost if a bank is resolved. This is in line with the empirical evidence in Bennett and Unal (2014) who estimate that around 12\% of bank assets are lost in FDIC resolutions ${ }^{13}$ Such resolution costs will be important in motivating the government's willingness to bail out failing banks and keep them operating as 'going concerns'.

\subsection{Investors}

Investors are risk neutral agents (of size 1) with endowments in periods $t$ of $A_{t}$ for $t=0,1,2$. They consume in periods 1 and 2 with preferences given by $c_{1}+\frac{c_{2}}{R}$. The assumption that investors discount at $\frac{1}{R}$ will determine the asset returns in equilibrium.

In the first period, investors allocate their endowment to the purchase of government debt $\left(b_{0}^{I}\right)$, bank equity $\left(x_{0}\right)$ and illiquid investments $\left(i_{0}^{I}\right)$. Their budget constraint in period 0 is:

$$
A_{0}=q_{0} b_{0}^{I}+x_{0}+i_{0}^{I}
$$

Their budget constraint in period 1 is:

$$
c_{1}^{I}(s)=A_{1}+q_{1}(s)\left(b_{0}^{I}-b_{1}^{I}(s)\right)-L_{1}^{I}(s)
$$

as the investor can purchase government debt of $b_{1}^{I}(s)-b_{0}^{I}$ and lend to banks, $L_{1}^{I}(s)$. The budget constraint in period 2 is:

$$
c_{2}^{I}\left(s, \mathbb{1}_{G}\right)=\left(1-\tau\left(\mathbb{1}_{G}\right)\right) A_{2}\left(\mathbb{1}_{G}\right)+b_{1}^{I}\left(\mathbb{1}_{G}\right)+R i_{0}^{I}+\delta_{2}\left(s, \mathbb{1}_{G}\right)+r^{b}(s) L_{1}^{I}(s)
$$

where $\tau$ is the tax rate on investors' endowments. In period 2, the endowment of the investor is augmented by the returns to bond holdings and the long term investments plus the repayments on bank loans. The government default decision influences investor consumption through the tax rate, the investors' endowment (explained below) and the return on bonds.

The investors' endowment at the final date, $A_{2}$, serves as the tax base for debt service. Its value depends on the default choice of the government. As in Eaton and Gersowitz (1981) and the literature that followed, government default leads to output costs. This is reflected in the $\left(1-\gamma \mathbb{1}_{G}\right)$ term in the investors' endowment where $\mathbb{1}_{G}=1$ if the government defaults. Specifically, the investor's endowment in the last period is given by:

$$
A_{2}=\bar{A}\left(1-\gamma \mathbb{1}_{G}\right)
$$

To be clear, our timing of events in the model implies that the default choice of the government does not directly impact the banking system. By the time default takes place at $t=2$, the

\footnotetext{
${ }^{13}$ To be clear, these do not refer to the loan losses that made the bank fail in the first place. The costs identified in the paper are expenses incurred in the actual process of resolving the failed bank.
} 
intermediation process is complete, which is why the cost of sovereign default is implemented via the exogenous partial endowment loss as in Eaton and Gersowitz (1981). In contrast, Gennaioli, Martin, and Rossi (2013) microfound output losses from sovereign default by assuming a timing where default occurs in the middle of the intermediation process, therefore disrupting it and causing a decline in investment and economic activity.

Our different timing reflects our emphasis on beliefs about default triggering a sovereignbanking loop as opposed to the actual occurrence of default. For the existence of a sovereign-banking amplification loop, two things are essential. Firstly, the government must still be able to issue debt in response to investor beliefs about its solvency as well as the financial health of banks. Secondly, the price of sovereign debt must react endogenously to the actions of the government as well as investors' beliefs about its likelihood of repayment. Exogenous default costs are a simplification that allow us to focus on the issue we are interested in but do not affect the nature of our results.

\subsection{The Government}

The government issues debt $B_{0}$ at price $q_{0}$ in period 0 to fund government expenditure $G_{0}$. This is two-period debt with repayment due in period 2. At the middle date, it issues additional debt to finance period 1 government expenditure $G_{1}$ and, if it chooses, makes transfers to support the banking system. At the end of period 1 , the debt outstanding is $B_{1}\left(q_{1}\right)$.

The multiplicity of debt valuations is dependent upon two features of the model, First, the government issues debt in the middle period. Second, the quantity of the debt issued must depend upon beliefs of agents in the middle period. This is accomplished by assuming that the government is committed to financing a fixed level of expenditures in the middle period, either to finance $G_{1}>0$ or a bank bailout 14

We assume that the size of time 0 government spending is smaller than the deposits of households in the bank. This makes it feasible for banks to buy the entire government debt stock which is convenient in the construction of the pessimistic equilibrium with government intervention.

Assumption 1. $d>G_{0}$.

\subsubsection{The Dependence of $B_{1}$ on $q_{1}$}

The dependence of the debt issuance in the middle period on $q_{1}$ is a key element of the analysis. In fact, $B_{1}\left(q_{1}\right)$ is a decreasing function of $q_{1}$.

A first reason for $B_{1}\left(q_{1}\right)$ to be contingent on $q_{1}$ comes from government spending ${ }^{15}$ Suppose the

\footnotetext{
${ }^{14}$ As pointed out by a referee, it is key that the government is committed to $G_{1}$ rather than simply choosing the face value of its debt. In Section 7 we relate this source of multiplicity to the analysis in Cole and Kehoe (2000). See Guo and Harrison (2008) for a discussion of timing assumptions of the government in models of multiple equilibria. For the multiplicity that arises through the bailout, there is no commitment to a level of spending as the bailout is a choice of the government.

${ }^{15}$ As suggested by a referee, this case is closest to Calvo (1988).
} 
government is committed to spending $G_{1}>0$ in period 1 . It must sell new debt of $\frac{G_{1}}{q_{1}}$ to finance this level of real spending. A second reason for $B_{1}\left(q_{1}\right)$ to depend on $q_{1}$ comes from government support of the banking system through bailouts of banks' sovereign debt holdings. Recall from (1) that banks expect state contingent government transfers $T\left(q_{1}(s), b_{0}\right)$. We will devote considerable space to explaining how these transfers are chosen. For now, it is sufficient to say that, if the government finds it optimal to provide such support, it will occur in states in which the value of government debt falls below the value needed to provide the bank's depositors will their promised repayments. Hence, without loss of generality, we assume that the government support takes the form of debt repurchases at above market values ${ }^{16}$

This implies that support of the banking system is inversely related to the value of government debt in period 1. A reduction in $q_{1}$ can lead to the deterioration of bank balance sheets, bank failures and thus the provision of financial support for these intermediaries. By assumption, the government sells additional debt to finance these transfers.

Specifically, consider a scheme in which the government buys back debt from banks at a target price $q_{1}^{T}$. Therefore it makes an aggregate transfer of:

$$
T\left(q_{1} ; q_{1}^{T}, B_{0}^{B}\right)=B_{0}^{B}\left(q_{1}^{T}-q_{1}\right)
$$

where $q_{1}^{T}$ is the buyback price of debt and $q_{1}$ is the prevailing price of debt under pessimism. Here $B_{0}^{B}$ is the total amount of debt held by the banking system at the start of period 1 . We will describe the government's decision problem shortly.

With this notation, we make explicit the dependence of the transfer on the buyback price for debt, the second argument, and the level of debt held by the banks, the third argument. The transfer in (3) is simply a bank specific version of (11) with $B_{0}^{B}$ replaced by the individual bank's holding of government debt.

For notational convenience, denote by $T\left(q_{1}\right)$ the transfers to the banking system when the current price of debt is $q_{1}$, suppressing the dependence of the transfer on bank holdings and the target price. The debt outstanding at the end of period 1 is

$$
B_{1}\left(q_{1}\right)=B_{0}+\frac{G_{1}+T\left(q_{1}\right)}{q_{1}} .
$$

In the construction of an equilibrium, the value of government debt in the middle period will be linked to the state, including the expectations of investors about debt repayment. Finally, we will allow the government to decide whether or not to support the financial system, thus making the dependence of $B_{1}$ on $q_{1}$ through this channel endogenous.

\footnotetext{
${ }^{16}$ Equivalently, the support could be in the form of deposit insurance.
} 


\subsubsection{Taxation and Default}

The government taxes investors' endowments $A_{2}$ at the final date. The tax rate required to meet the total obligations of the government is equal to

$$
\tau=\frac{B_{1}\left(q_{1}\right)}{A_{2}} .
$$

By taxing investors' endowments, the government taxation does not directly impact the intermediation process. Any frictions that impinge on the deposit contract, such as sequential service, are irrelevant for the government's ability to collect taxes.

To introduce the possibility of default into the analysis, assume the government's capacity to tax the endowment of the investors is random and drawn from a known probability distribution $F(\tilde{\tau})$ with associated density $f(\tilde{\tau}){ }^{17}$ The uncertainty about tax capacity, denoted $\tilde{\tau}$, is realized at the final date. This naturally leads to the possibility of default due to bad fundamentals (as opposed to strategic default): a low realization of $\tilde{\tau}$ could trigger government insolvency despite a large tax base $\left(A_{2}\right) \cdot 18$

If $\tilde{\tau}<\frac{B_{1}\left(q_{1}\right)}{A_{2}}$, the government must default on its obligations. The probability of default is therefore equal to $F\left(\frac{B_{1}\left(q_{1}\right)}{A_{2}}\right)$ while the probability of repayment is given by $1-F\left(\frac{B_{1}\left(q_{1}\right)}{A_{2}}\right)$. Once the government is forced to default, it defaults fully. But, if $\tilde{\tau}>\frac{B_{1}\left(q_{1}\right)}{A_{2}}$, the government repays its debt obligation. No additional taxes are collected.

To capture the idea that there is some certainty to the government revenue stream, assume $\tilde{\tau}=\bar{\tau}+\xi$ where $\xi>0$ is random. Here $\bar{\tau}$ represents the non-stochastic part of tax capacity. The government is assured revenue of $\bar{\tau} A_{2}$.

\subsubsection{The Government's Bailout Choice Problem}

While the government's default decision in the last period is determined by its exogenous debt capacity, the government makes a key decision in the model: its choice in the middle period to bailout the banks. This is a key element in the diabolic loop. If the government does not bailout the banks, then the loop disappears.

Understanding the government's incentives to provide a bailout is complicated since this decision is made along an equilibrium path. As we construct a number of equilibria, there is no single simple expression for the choice problem of the government.

Intuitively, the government faces the following trade-off that underlies the analytics developed in the proofs of Propositions 2 and 3. Assume there is pessimism about the government's ability to repay its debt in the final period. Consequently the value of government debt is low and banks, who chose not to issue equity, are in trouble. If the government allows the banks to fail, there is a

\footnotetext{
${ }^{17}$ Alternatively, $A_{2}$ could be random. In this formulation, these approaches are equivalent.

${ }^{18}$ Section 7.2 discusses the case of strategic default.
} 
cost of bank resolution. If the government bails out the banks it must issue more debt to finance these transfers. This further reduces the likelihood of repayment on its debt obligations in the last period and thus increasing the likelihood of incurring the default cost.

The government's choice under pessimism to bailout the banks depends on these costs and benefits. Importantly, this choice, which is anticipated by the banks influences the portfolio decision of banks and their equity issuance. Thus the government and bank choices are jointly determined in equilibrium.

\section{Debt Prices}

This section characterizes equilibria in the period 1 market for government debt. The discussion highlights the existence of multiple equilibria in this market.

As noted earlier, the model includes two sources of multiplicity in the debt markets. One arises from a government policy to bail out troubled banks. The other comes from a fiscal policy that stipulates a fixed level of real spending. This section explains how these two sources can generate multiple equilibria. As we demonstrate, the multiplicity of equilibria can arise even if there is no government spendings in the middle period, $G_{1}=0$, as long as the government is unable to commit not to bailout the banks. The role of $G_{1}>0$ is apparent in evaluating the role of bank equity.

These two sources of multiplicity will be used to construct sunspot equilibria. They are also used to examine the effects of government actions, such as a commitment not to bailout banks.

\subsection{Arbitrage Condition}

In period 1 , the debt is priced by the risk neutral investors who discount the future at rate $\frac{1}{R}$. The price $q_{1}$ is determined by a no-arbitrage condition.

Given a debt buyback scheme, there are transfers to the banking system, i.e. $T\left(q_{1}\right)>0$ for all $q_{1}<q_{1}^{T}$. In this setting the risk neutral investor's condition for an interior demand for government debt (a condition for no-arbitrage) becomes:

$$
\frac{1-F\left(\frac{B_{0}+\left(G_{1}+T\left(q_{1}\right)\right) / q_{1}}{A}\right)}{R}=q_{1}
$$

The left side of (13) is increasing in $q_{1}$. As $q_{1}$ increases, the amount of debt outstanding decreases as transfers are lower and thus the probability of repayment increases with $q_{1}$.

This highlights the underlying complementarity of the model and thus the multiplicity in debt valuations. Generally creating multiple solutions to (13) amounts to the choice of a distribution function $F\left(\dot{)}\right.$ such that the left hand side, graphed as a function of $q_{1}$ has multiple crossing with the 45 degree line.

We study more specific solutions to 13 by focusing on the two sources of multiplicity. First, are the government transfers to support the banks which we highlight by assuming $G_{1}=0$. Second 
is the financing of middle period government spending which we study under the assumption of no transfers to the banks, $T\left(q_{1}\right)=0$ for all $q_{1}$.

\subsection{The Effects of Bailouts: $G_{1}=0$}

This section studies the case in which there are no government purchases in the interim period. The multiplicity of solutions to the debt valuation equation is created entirely by the government bailout policy, $T\left(q_{1}\right)$. This case allows us to highlight the role of expectations about bailout on the creation of debt fragility.

We start by making the assumption that the government has enough revenue to cover $B_{0}$, so $F\left(B_{0}\right)=0$. This is a restriction on the level of inherited debt, $B_{0}$ and the non-stochastic part of the tax system.

Assumption 2. $\bar{\tau} A_{2} \geq B_{0}$.

This assumption implies that if $T\left(q_{1}\right) \equiv 0$, then the only solution to 13 is the debt price with certain repayment, denoted $q_{1}^{*}$. As developed further below, this debt price coincides with an optimistic equilibrium in which there is no default and no debt fragility so that $q_{1}^{*}=\frac{1}{R}$. While not essential for our results, this assumption helps us focus on sovereign default risk that arises from self-fulfilling bailout expectations.

If, however, the government bails out banks so that $T\left(q_{1}\right)>0$ for some $q_{1}$, then multiple solutions to (13) become possible. This is because, a decline in the debt price increases the needed bailout assistance $T\left(q_{1}\right)$ making the debt endogenously riskier and validating the pessimistic expectations. A leading case is one in which the bailout sets $q_{1}^{T}=q_{1}^{*}$ in (11) so that the value of government debt held by banks is supported at the optimistic equilibrium price. Below, we provide conditions under which a bailout at this target price is feasible.

It might also be the case that there are no solutions to 13 under a policy that fully compensates banks for losses on sovereign bond holdings, i.e. $q_{1}^{T}=q_{1}^{*}$. That is, there may be no price for debt satisfying (13) that provides enough resources so that a government's intended buyback scheme is feasible. In that case, we expand the analysis to include partial bailout.

Formally, let $q^{\max }$ be the maximal value of the target price, $q_{1}^{T}$, such that an interior solution to (13) exists. From (13), $q^{\max }$ depends on the amount of debt held by banks. If $q^{\max }=q_{1}^{*}$, then a government buyback program to support the price of period 1 bank-held debt at $q_{1}^{*}$ is feasible.

If $q^{\max }<q_{1}^{*}$, then a full buyback scheme is not feasible but a partial buyback at a debt price less that $q_{1}^{*}$ is feasible. We formalize these possibilities through these two assumptions to be invoked below. These cases are illustrated in the example that follows.

Condition 1. A full debt buyback is feasible: $q^{\max }=q_{1}^{*}$.

Condition 2. A partial debt buyback is feasible but a full buyback is not feasible: $0<q^{\text {max }}<q_{1}^{*}$. 


\subsubsection{Example}

Figure 1:

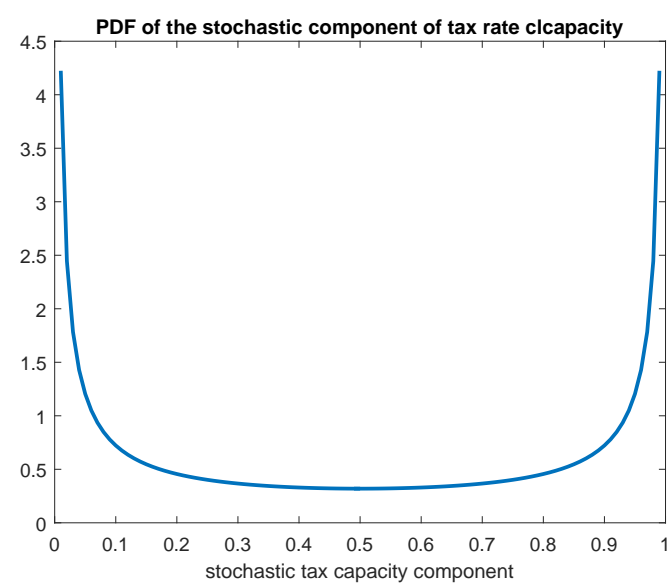

This figure shows the distribution of the stochastic component of the tax rate capacity.

We construct a specific numerical example to illustrate the multiplicity of equilibria. The example assumes a Beta $(0.2,0.2)$ distribution for the stochastic component of the tax system, $\xi$, and sets $B_{0}=0.56, B_{0}^{B}=0.28$ (i.e. banks hold half the government debt) and $\bar{\tau}=0.6$. For this example, $R=1.0$. The pdf of the distribution of the stochastic component of the tax capacity variable is given in Figure 1 .

The transfer scheme is given by (11) with a target of $q_{1}^{*}$. The size of the debt buyback is related to the size of the bank's holdings of government debt, denoted $B_{0}^{B}$. The pricing equation under pessimism when the government provides a bailout is given by (13).

This distribution of tax rates is bimodal. With high probability, the tax capacity is simply $\bar{\tau}$. In this case, the government may be unable to cover debt obligations beyond $60 \%$ of output. The second mode is at a very high tax rate, allowing the government the ability to meet very large obligations. Though outside the model, this may reflect considerable disagreement among political parties regarding taxation.

The model's implications for the debt pricing equation are given in Figure 2. There are three lines in the figure. The blue line (labelled 'No bailout' in the legend) depicts the case where there are no bailouts and the government debt is safe regardless of the bond price in the market. Intuitively, since Assumption 2 is satisfied, the debt can always be repaid whenever the government does not incur any other expenditures at date 1 .

The red line is the baseline model with $T\left(q_{1}\right)>0$. Here due to the need to make transfers to the banks, there is a multiplicity of equilibria. In the specific example we compute, there are five equilibria. At one extreme is the 'collapse equilibrium' where the government defaults with probability one and thus $q_{1}=0$. At the other extreme we have an equilibrium, labeled 'OE' in the figure and standing for 'optimistic equilibrium', with a repayment probability equal to unity and 
$q_{1}=\frac{1}{R}$. This is the same equilibrium as the one under no bailouts since the probability of sovereign default is zero.

Figure 2:

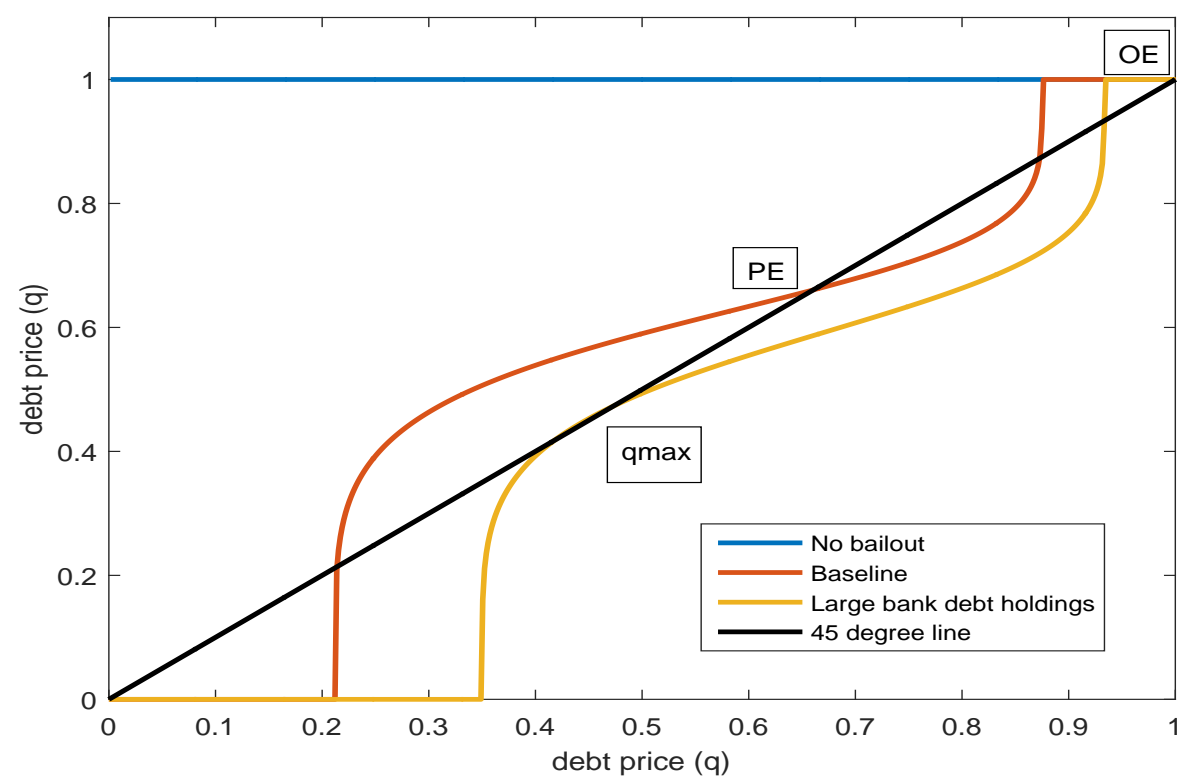

This graph shows the multiple solutions to the no-arbitrage condition with $G_{1}=0, T\left(q_{1}\right)>0$ and $q_{1}^{T}=q_{1}^{*}$.

In the interior of the debt price distribution we have three equilibria in which a positive probability of sovereign default is self fulfilling. One of these equilibria is locally stable under best response dynamics. We focus on the locally stable equilibrium in our construction of sunspot equilibria. It is labeled 'PE' in Figure 2 and we refer to it as the 'pessimistic equilibrium'. At this equilibrium, $q_{1}=0.661$.

Included in Figure 2 is also a yellow line which is drawn under the assumption that the bank's debt holdings are equal to $B_{0}^{B}=0.56$. This has the same effect as changing the target price - it shifts the entire debt pricing curve downwards. Eventually, as the bank debt holdings get larger, many interior equilibria disappear, leaving the stable 'pessimistic equilibrium' as the point of tangency in Figure 2. This point also gives the maximum bank holding of government debt under which a full government bailout is feasible. This point is the same as $q^{\text {max }}$ defined above.

Higher bank holdings of government debt can only be partially bailed out. The total bailout size at the point of tangency in Figure 2 shows the maximum bailout size. If banks hold more government debt than this or if the target price is higher, only a partial bailout can be provided.

\subsubsection{Multiple Debt Prices}

In general, Assumption 2 implies that there is always an equilibrium with $q_{1}=q^{T}$ since there are no transfers in this case and thus a unique solution to 13 . If $q_{1}<q^{T}$, then the government 
participates in the debt buyback and $T\left(q_{1}\right)>0$. This creates the possibility of multiple solutions to (13) since both sides are increasing in $q_{1}$.

As the interest of this paper is not in determining the conditions for multiple solutions to the debt equation, we assume this is the case. This assumption is based upon a target of $q_{1}^{*}$.

Assumption 3. With $q^{T}=q_{1}^{*}$ and $G_{1}>0$, there exists a tax capacity distribution such that there are multiple solutions to (13), including $q_{1}=\frac{1}{R}$ and a locally stable solution with $q_{1}<\frac{1}{R}$.

This assumption is not vacuous for two reasons. First, the example given above has these properties. Second, the multiplicity in the example, and more generally associated with other distributions, is generic. That is, small variations in the fundamentals do not alter the number of equilibria.

\subsection{Government Purchases Only: $T\left(q_{1}\right) \equiv 0$}

It is also of interest to understand the multiplicity of solutions of the debt pricing equation even if the government does not bailout banks. That is, here we impose a no bailout policy with $T\left(q_{1}\right)=0$ for all $q_{1}$ but allow interim government purchases, $G_{1}>0$.

In this case, (13) simplifies to:

$$
\frac{1-F\left(\frac{B_{0}+G_{1} / q_{1}}{\bar{A}}\right)}{R}=q_{1}
$$

Importantly, the left side is still increasing in the price of government debt, thus creating the potential for multiple solutions. Further, we will assume that there remains an equilibrium without default and thus $q_{1}=q_{1}^{*}$. We make this assumption more formal in the following section.

\subsubsection{Example}

The following example is drawn for the same tax capacity distribution as in the previous section and for $G_{1}=0.04$. It illustrates the multiplicity of equilibria when there are no bailouts but the government needs to finance government expenditure at the middle date.

The figure shows that a similar set of equilibria exists when multiplicity arises due to $G_{1}>0$. Just as in the previous section, the multiplicity arises due to the government having to issue more debt when the debt price is low. In the previous case we considered, the greater issuance arose out of a need to bail out the banks. Here it arises out of the need to finance government expenditure which is fixed in terms of goods.

\subsubsection{Multiple Debt Prices}

More generally, both the left and right sides of (14) are increasing in $q_{1}$. This creates the possibility of multiple solutions to 13 . 
Figure 3: Multiple Solutions with $G_{1}>0$

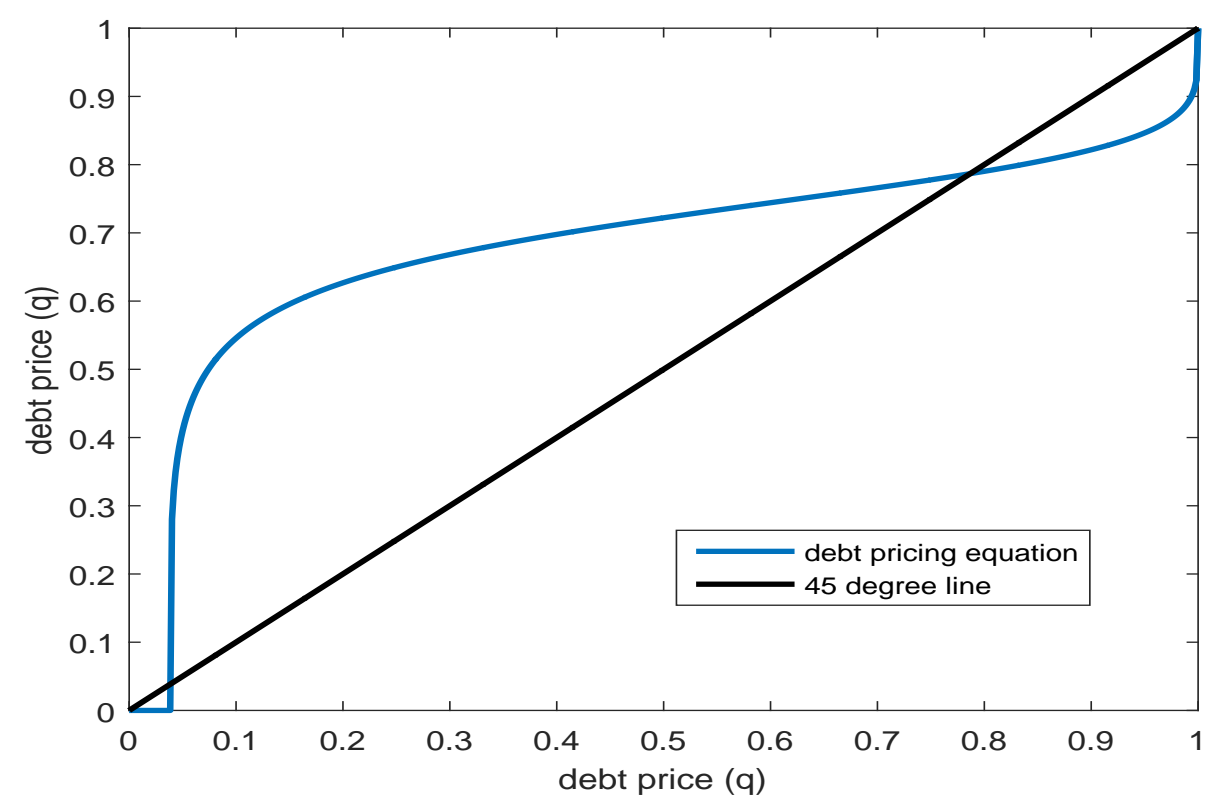

This graph shows the multiple solutions to the no-arbitrage condition with $G_{1}>0$ and $T\left(q_{1}\right)=0$.

Assumption 4. With $T\left(q_{1}\right)=0$ for all $q_{1}$ and $G_{1}>0$, there exists a tax capacity distribution such that there are multiple solutions to (14), including $q_{1}=\frac{1}{R}$ and a locally stable solution with $q_{1}<\frac{1}{R}$.

As in the case of government bailout of banks, this assumption is not vacuous. Again, the example makes clear that multiple equilibria may arise.

\section{Subgame Perfect Nash Equilibria}

The analysis focuses on Subgame Perfect Nash Equilibria (SPNE). These are constructed from two key components of the model. The first is the market for government debt in period 1. As suggested in the discussion above, this is the source of multiplicity. The second component is the bank contract and equity choice of the bank in period 0 .

A Sub-game Perfect Nash Equilibria builds on the equilibria in the period 1 debt market. The players are the banks, the households and the government. The banks simultaneously and independently move first, setting contracts with households and deciding on their portfolio, including the amount of equity financing. These contracts are set in period 0 , recognizing the possibility of strategic uncertainty influencing the valuation of government debt in period 1 as well as any government support.

Definition 1. A Sub-game Perfect Nash Equilibrium (SPNE) is a set of bank equity issuance, contracts with depositors and debt purchase strategies, a set of government bailout provision 
strategies and a set of realizations of government debt prices as a function of the debt sunspot realizations such that: (i) Individual banks solve (1) given the government's bank bailout strategy, the exogenous probabilities of government debt sunspot shock realizations and the prices of government debt at these sunspot realizations, (ii) the government chooses whether or not to bailout the banks in order to maximize social welfare taking bank government debt exposures as given, and (iii) the government debt markets clear at each sunspot realization.

We construct sunspot equilibria as a randomization between two equilibria. One arises when banks believe that the government will repay its debt with probability one. In this outcome, which we term an 'optimistic equilibrium', there is no default premium on the debt.

The second outcome occurs when investors are pessimistic about the government repayment of the debt. In this equilibrium, banks believe the the government will provide a bailout. We term this state 'pessimism' since the outcome in the debt market includes a default premium.

These equilibria are solutions to (13). In the earlier example without government purchases $\left(G_{1}=0\right)$, these were labeled 'OE' and 'PE' in Figure 2. However, nothing rests on the selection from the set of solutions to 13 with $q_{1}<q_{1}^{*}$ under 'pessimism'.

Along the equilibrium path, the expectations underlying the choices of the investors, depositors and the banking contract are fulfilled. This is part of a sub-game perfect Nash Equilibrium.

The existence of SPNE with sunspots will depend on the government's ability to commit to a bank bailout policy. At one extreme, a weak government is incapable of any kind of commitment and decides whether or not to bailout a financial institutions in period 1. At the other extreme, a committed government chooses ex ante, i.e. in period 0, whether to bailout the banks. ${ }^{19}$

Our approach is to study two cases. This is achieved in the following two sections.

\section{No Commitment: Fragility and Bailouts}

This section constructs SPNE in which sunspots matter. It does so for the leading case in which there are no government purchases in the middle period, $G_{1}=0$. The analysis thus highlights the role of beliefs about government bailout for debt fragility. The next section allows $G_{1}>0$ to become another source of multiplicity, as in section 3.3 , when we analyze government commitment and bank equity.

The beliefs of investors in period 1 determine the value of government debt and this in turn impacts the banks. There are two main features of these equilibria. First, the government chooses to bailout the banks. Second, the banks choose to hold no equity.

The sunspots are randomizations between an 'optimistic equilibrium' in which there is no default risk and a 'pessimistic equiliibrium' with default risk. An interesting feature of the construction is

\footnotetext{
${ }^{19}$ Here the government is limited to choosing bailout or no bailout, including the imposition of a tax on investors to finance these flows. We do not consider other ex ante tools for redistribution.
} 
that the pessimistic equilibrium only exists because of government support of the banks. And the banks only need to be supported because of the pessimistic expectations.

\subsection{Optimistic Equilibrium}

The optimistic equilibrium has zero default risk and no fragility in debt prices. It is used in the construction of a sunspot equilibrium and interesting in its own right because debt markets can function perfectly well in our economic environment. We will also use this equilibrium as a basis for welfare comparisons.

\subsubsection{Optimal Contract}

Given debt prices $q_{0}=q_{1}=\frac{1}{R}$, the optimal contract between the households and the banks solves (1) subject to the constraints as described in section 2.2. This problem generates a demand for government debt by the banking system. In an optimistic equilibrium, neither the banks nor the depositors anticipate variations in the price of government debt as sunspots, by construction, do not matter.

The banks hold a portfolio of government debt and long-term illiquid investment. They provide for the consumption of early households by selling government debt to investors in period 1 . When the liquidation value of the illiquid investment, $\varepsilon$, is less than one, trading government debt strictly dominates liquidating the long-term investment. At $\varepsilon=1$, the bank is indifferent between liquidation and the selling of government debt and we assume there is no liquidation in this case either.

Lemma 1. In the optimal banking contract with no default risk and $q_{0}=q_{1}=\frac{1}{R}$ : (i) $c^{L}>c^{E}$, (ii) $l_{1}=0$ and (iii) $x_{0}=0$.

Proof. See Appendix, Section 9.3.1.

In the subsequent discussion, let $\left(c^{* E}, c^{* L}\right)$ denote the optimal contract characterized in Proposition 1. We will refer to this as the first best contract.

The proof comes directly from the first-order condition of the optimal contracting problem. Given the assumed optimism, there is no uncertainty over the valuation of debt and thus no aggregate risk to share. The property that $c^{* L}>c^{* E}$ implies that depositors have an incentive to reveal their true taste types.20

From (1), there are other elements of the bank's problem to determine. To implement the optimal contract, it is sufficient that debt holdings of the bank satisfy: $\left(b_{0}=\frac{\pi c^{* E}}{q_{1}}, i_{0}=\frac{(1-\pi) c^{* L}}{R}\right)$. Further, $\left(b_{1}=L_{1}=0\right)$ as trades in period 1 are not needed in the case of optimism. In an optimistic

\footnotetext{
${ }^{20} \mathrm{As}$ is well understood, there may also exist a bank runs equilibrium in this environment. That is not the focus of this analysis and is initially left aside to focus on crises emanating from uncertainty over government debt repayment. We return to this in Section 7.3 .
} 
equilibrium, bank equity, $x_{0}$ is irrelevant to the allocation of the households. Thus for convenience, we set $x_{0}=0$ in the construction of an optimistic equilibrium. Equity will play a more important role in the sunspot equilibrium later on in the paper.

\subsubsection{Equilibrium}

Given the banking contract, the last step in constructing an equilibrium is to guarantee market clearing. There are three markets to consider: (i) the period 0 market for government debt, (ii) the period 1 market for government debt and (iii) the interbank loan market. Let $\left(q_{0}^{*}, q_{1}^{*}\right)$ denote the values of the debt prices in an optimistic equilibrium.

Proposition 1. Under Assumption 2, there exists an optimistic rational expectations equilibrium with $q_{0}^{*}=q_{1}^{*}=\frac{1}{R}, r^{b}=R$ and the banking contract given by $\left(c^{* E}, c^{* L}\right)$.

Proof. See Appendix, Section 9.3.2.

We refer to the allocation characterized by Proposition 1 as the first best allocation. The proof of the proposition takes the banking contract characterized in Proposition 1 and shows that with this contract, markets clear at $q_{0}^{*}=q_{1}^{*}=\frac{1}{R}$. In this equilibrium, risks are shared efficiently between the risk averse household and investors through the banking system. Further, there are no resources lost due to default and/or bank resolutions. From Assumption 2, there is no default in equilibrium. In this way, this allocation will serve as a benchmark for ex ante comparisons of other allocations.

We assume that at this allocation, a government with the ability to redistribute the endowments of households and investors in period 0 would have no incentive to do so. This implicitly defines a welfare weight for investors in period $0, \omega$, such that $u^{\prime}\left(c^{* E}\right)=\omega \cdot 21$

This is a benchmark equilibrium for this economy in which there is no strategic uncertainty and no default. This equilibrium is constructed on the assumption, fulfilled in equilibrium, that the government will not bailout banks. Thus $T\left(q_{1}\right) \equiv 0$ and thus the multiple solutions to (13) disappear.22

Under discretion though, other equilibria might exist if investors believe the government may default and, if debt prices decline, provide a bailout to banks. This activates the multiplicity inherent in $(13)$. We study these equilibria next.

\subsection{Debt Fragility and Bailouts}

This section constructs sunspot equilibria. These equilibria entail both debt fragility and government bailouts of banks.

\footnotetext{
${ }^{21}$ This comes from a planner's problem allocating the deposit of households between illiquid investment and government bonds that yield, as in an optimistic equilibrium, a return of unity between period 0 and period 1 .

${ }^{22}$ This is where the assumption of $G_{1}=0$ comes into play.
} 
Throughout we maintain Assumption 3. Else, there would be no debt fragility. The construction is based upon a randomization between a solution to 13 with $q_{1}<\frac{1}{R}$ and the no-default equilibrium where $q_{1}=\frac{1}{R}$. For the example in Section 3.2.1, this is a randomization between the 'OE' and 'PE' points.

The sunspot equilibrium has a couple of key characteristics. First, banks anticipate a bailout by the government and hold no equity. Second, the government decides ex post to bail out the banks. Third, through the bailout, multiple solutions to (13) arise.

\subsubsection{Government's Choice: Bailout or Bank Resolution}

Characterizing the costs and benefits of a bailout are key to proving Propositions 2 and 3 below. The existence of these equilibria requires the government to have an incentive to bailout the banks. The conditions of the proposition, low default cost and high resolution costs provide incentives for the government to support the banks.

In order to construct the equilibrium with bailout, it is necessary to specify what happens in the event the government chooses, off the equilibrium path, not to engage in a debt buyback scheme. As banks anticipated this bailout, if it is not provided, they are insolvent: i.e. their liabilities to depositors exceed their assets.

In this case, the banks need to be resolved. Section 9.2 outlines a resolution mechanism that has two key features. ${ }^{23}$ First, it is efficient: if the government does not bailout a bank, then the insolvent bank is liquidated allowing assets to be used to pay off depositors in an optimal way. This involves no government help or sovereign debt issuance and is simply an efficient write-down of depositors' claims to the new (lower) value of bank assets. Second, bank resolution is costly. A fraction $\psi$ of total deposits is lost in the resolution process. This cost is distinct from the cost of government default and represents the administrative and legal costs of resolving failing banks or the inferior loan management skills of regulators as opposed to private banks. Bennett and Unal (2014) present empirical evidence for the existence of large costs of this nature.

\subsubsection{Sunspot Equilibria}

The following proposition provides conditions for the existence of a SPE with strategic uncertainty. The key to constructing the sunspot equilibria is providing conditions such that a government will choose, ex post, to support the banking system through a full debt buyback, i.e. $q_{1}^{T}=q_{1}^{*}=\frac{1}{R}$. The proposition makes clear the response of the banks to the prospect of a bailout.

Proposition 2. If Condition 1 holds and

1. either (i) the default cost, $\gamma$, is sufficiently small or (ii) the cost of resolving the banking system, $\psi$, is sufficiently large, there will exist a SPNE with a government debt buyback at a

\footnotetext{
${ }^{23}$ The procedure is related to that studied in Ennis and Keister (2009) and Cooper and Kempf (2015).
} 
price of $q_{1}^{T}=\frac{1}{R}$ in the pessimistic sunspot state. The first best banking contract is offered to households supported by a bailout in the pessimistic state. No equity is issued by the bank.

2. the default cost, $\gamma$, is sufficiently large and the cost of resolving the banking system, $\psi$, is sufficiently small, there will not exist a SPNE with a government debt buyback at a price of $q_{1}^{T}=\frac{1}{R}$ in the pessimistic sunspot state.

Proof. See Appendix, Section 9.3.3.

Absent commitment, in the pessimistic state the government will choose in period 1 whether to bailout the banks or not. There are three factors influencing the bailout decision which are made explicit in the proof. First, relative to an allocation without a bailout, there are gains to redistribution from investors to depositors. This motivates a bailout. Second, if bankruptcy costs $\psi$ are high, then there are gains to bailout from avoiding these costs. Third, as the bailout is debt financed, it may increase the probability of default. The magnitude of this cost depends on the size of $\gamma$ as well as the sensitivity of the probability of default to changes in the amount of debt outstanding. In our model, this last effect will depend on the shape of $F(\cdot)$ in the neighborhood of a pessimistic equilibrium.

The sufficient conditions for bailout, given in the first part of the proposition, reflect these tradeoffs. If $\gamma$ is low, then bailout is provided because redistribution through government support is desired and saving the financial sector is important. Even if there are costs of sovereign default, as long as $\psi$ is large enough, bailout will be desired.

The second part of the proposition provides sufficient conditions for a full bailout not to occur. Given the tradeoff between the government default cost and the gains from saving the banking system, if the default cost is large enough relative to the cost of resolving insolvent banks, then the bailout equilibrium will not exist. In that case, the only equilibrium is the optimistic one where there is no strategic uncertainty and only a weak incentive for banks to issue equity.

Condition 1 is used in Proposition 2 to guarantee that a pessimistic equilibrium exists under a full debt buyback scheme. If this assumption does not hold, then a full buyback is not feasible. The government is simply not able to borrow enough to finance the transfers to the banks which are needed for a full debt buyback.

Suppose that instead Condition 2 holds so that only a partial bailout is feasible. There is a maximal level of debt the government could incur while maintaining a positive probability of repayment.

The next result finds that a government will provide a partial bailout if it is feasible and if it avoids incurring bank resolution costs. The banks provide the remaining insurance to households by issuing equity and avoiding bankrupcty.

Proposition 3. Suppose Condition 2 holds and the government lacks commitment. If 
1. either (i) the default cost, $\gamma$, is sufficiently small or (ii) the cost of resolving the banking system, $\psi$, is sufficiently large, there will exist a SPNE with a government debt buyback at a price of

$q_{1}^{\max }<\frac{1}{R}$ in the pessimistic sunspot state, where $q_{1}^{\max }$ is the maximum buyback price such that a pessimistic equilibrium exists. The first best banking contract is offered to households, supported by a combination of investor equity and a partial bailout in the pessimistic state.

2. the default cost, $\gamma$, is sufficiently large and the cost of resolving the banking system, $\psi$, is sufficiently small, there will not exist a SPNE with a government debt buyback at a price of $q_{1}^{\max }$ in the pessimistic sunspot state.

Proof. See Appendix, Section 9.3.4.

\subsection{Bank Equity}

A prominent feature of the two equilibria characterized in these propositions was the role of bank equity. In Proposition 2 the bailout of banks by the government created an incentive for banks not to issue any equity. This choice does not reflect a high opportunity cost of issuing equity. Rather, the fact that governments save banks that get in trouble due to losses on sovereign debt holdings creates the incentives for banks to expose themselves to sovereign default risk in the first place. High exposure takes two forms. First banks hold more government debt than they need in order to provide consumption for early households. Second, they do not issue equity thus ensuring that they are insolvent when the value of government debt falls.

In the equilibrium of Proposition 2, banks anticipate the bailout and thus choose not to selfinsure through equity buffers. In fact, banks become the natural holders of risky government debt, buying the entire stock and pushing its price above the level that uninsured investors are willing to pay. A single bank cannot profitably deviate from such a Nash equilibrium by issuing equity because this will erode its bailout subsidy from the government and, as a result, government debt would become too expensive for such a financial institution. The large debt holdings and the absence of equity buffers add further contingent liabilities for the sovereign, thus activating the diabolic loop.

Only when faced with residual uncertainty over default, did banks issue some equity. In the equilibrium of Proposition 3, the incentives for the bank are different. While they have an incentive to take advantage of the government buyback program, they also profit by providing insurance to depositors. Taken together, these factors lead them to issue enough equity to cover the residual risk faced by depositors given the partial debt buyback of the government.

These equilibria crucially depend on the expectations of a bailout. In fact, there exists another Nash equilibrium in which banks do not expect to be bailed out in the event of failure and, as a result, they may choose to issue equity to buffer depositors against fluctuations in the value of government debt. In equilibrium, government debt becomes riskless and a bailout is not needed. debt becomes riskless. 
Proposition 4. When banks expect no bailout, they fully insure their depositors by issuing equity. The first best banking contract is offered. The government does not need to bail out banks and therefore strategic uncertainty in the debt market disappears.

Proof. See Appendix, Section 9.3.5.

Proposition 4 demonstrates that the bank has the options at its disposal in order to implement the first best contract without government assistance. To be clear, this equilibrium co-exists with the others characterized in Propositions 2 and 3 in which debt markets are fragile.

In this equilibrium, there are only weak incentives to issue equity. That is, if no government bailout is anticipated, then along the equilibrium path the only equilibrium in debt markets, from Assumption 2, is the optimistic equilibrium with $T\left(q^{*}\right)=0$. There is no strategic uncertainty in the debt market and thus no strict incentive for banks to issue equity.

This property is a consequence of our assumption that $G_{1}=0$. This assumption was made to make clear the role of government bailout in creating multiplicity. If $G_{1}>0$, then as discussed in section 3.3, there may exist multiple solutions to the $(14)$, even if where $T\left(q_{1}\right)=0$ for all $q_{1}$. This means that, in the absence of equity to absorb losses on sovereign bond holdings, bank depositors face risks even in the absence of government bailouts. In this case, even if banks anticipate no bailout they will have a strict incentive to issue equity in order to insure their depositors. The banking contract outcome will therefore coincide with the optimistic equilibrium. This is shown in the following proposition.

Proposition 5. In a sunspot equilibrium with $G_{1}>0$ and no government bailout, if Assumption 4 holds, banks will fully insure their depositors by issuing equity. The first best banking contract is offered.

Proof. See Appendix, Section 9.3.6.

\section{Commitment}

Without commitment, if the default $\operatorname{cost}(\gamma)$ is small, and the intermediation sector is costly to resolve ( $\psi$ is large), the government will be induced to support the financial system during a banking crisis. In this case, sunspot driven fluctuations in the value of government debt are ultimately absorbed by the investors who provide the taxes to support the banks. This form of risk sharing through the government is costly. Insofar as a bailout is financed by the issuance of new government debt, the higher debt burden increases the likelihood of sovereign default which carries deadweight costs.

As we saw in Proposition 4, there is another, more efficient, way to share the risk associated with debt fragility: through bank equity. As long as banks expect no government assistance in the event of insolvency, they will privately choose to insure depositors by building up equity buffers. 
The proposition below demonstrates the fact that if the government can commit to a no bailout policy, the banking system will self-insure and become immune to strategic uncertainty: there is no diabolic loop. In fact, since the key to the debt fragility is the government support of the banks, commitment to a no-bailout policy is sufficient to eliminate strategic uncertainty in the debt market.

Proposition 6. If $G_{1}=0$, a committed government will choose not to bailout the banks. In the SPNE, banks self-insure through equity issuance and provide the first best contract to households.

Proof. See Appendix, Section 9.3.7.

Proposition 6 shows that government discretion is a necessary ingredient for the existence of the 'diabolic loop'. A committed government that withholds bailouts ex post will induce banks to self-insure in a way that obviates the need for government assistance. The resulting allocation is identical to the optimistic equilibrium (first best allocation) characterized in Proposition 1.

Propositions 2 and 6 demonstrate how bank risk taking in the sovereign debt market grows and the joint fragility of banks and sovereigns worsens with diminished commitment. If governments can commit not to bail out, bank and sovereign balances sheets become disconnected and there is no sovereign-banking loop. When no commitment is possible, we get full moral hazard: banks over-invest in government debt and issue no equity. The probability of government default in the pessimistic equilibrium is higher under discretion than in the case of the government with commitment.

In both of these equilibria the households suffer no losses from the onset of pessimism in the debt market. But this happens in very different ways. In the equilibrium with commitment, the banks self insure through equity. So when there are variations in the value of government debt, the banks have a buffer.

In the equilibrium without commitment, there is no equity. The banks are insolvent following a pessimistic sunspot. The government steps in to protect depositors: this is a banking crisis, but not one that entails depositor losses. Because of the bailout, government debt is higher, thus increasing the chance of a costly default (when $\gamma>0$ ). This is the source of the welfare loss without commitment.

Absent the ability to commit, the government may take actions ex ante to make more credible a pledge of "no bailouts" ex post. As suggested by Proposition 2, ex ante actions to increase the costs of sovereign default along with measures to make it easier for banks to fail, will reduce incentives for ex post bailout. In our model, these actions reduce the value of $\psi$. Recent efforts to limit the importance of banks who otherwise might be "too big to fail" would be one example. Another is the increased reliance on explicitly 'bailinable' debt instruments in addition to insured deposits in banks' liability structure. Indeed, when bailouts are avoided, fragility in the sovereign debt market disappears.

As in Proposition 4, in equilibrium the bank's incentive to issue equity is weak since debt fragility 
disappears in the absence of a government bailout. In fact, Proposition 5 applies here as well 24 That is, if $G_{1}>0$ and there are multiple solutions to (14), then fragility will exist in the debt market and banks will have a strict incentive to issue equity.

\section{Extensions}

This section assesses the robustness of our findings on the existence of a diabolic loop to two features of our model. First, we consider an alternative model of strategic uncertainty in debt markets. Second, we allow for strategic default. Third, we examine how our analysis changes when we allow for the possibility of bank runs. We find that our findings are robust to these modeling choices.

\subsection{Debt Rollover}

In our model, multiple equilibria in the government debt market arise due to the feedback between debt issuance in the middle date (either to finance government expenditure or to bailout banks) and the interest rate on government debt. Higher interest rates necessitate higher issuance which increases the probability of default thereby validating the higher interest rates.

An alternative framework to generate multiplicity is the model of Cole and Kehoe (2000) which models dynamics where government default occurs due to difficulty in rolling over outstanding debt. This mechanism is absent from the baseline version of our model since all of the debt present in period 0 has a two-period maturity. Thus, there is no rollover decision in period 1 and the debt sold in period 1 is needed to finance either government purchases or a bank bailout.

To illustrate how debt rollover might enter into our model, suppose that an exogenous fraction $\lambda$ of the period 0 government debt matured in period 1. As already assumed in the model, period 1 expenditures are financed by newly issued debt. In this case, the evolution of government debt is given by:

$$
B_{1}\left(q_{1}\right)=(1-\lambda) B_{0}+\frac{\lambda B_{0}+G_{1}+T\left(q_{1}\right)}{q_{1}} .
$$

This is 12 with the added flow of $\lambda B_{0}$ on the one-period debt. There are a couple of main points about adding debt rollover to our model that are apparent from this expression.

First, as long as the government does not default in the middle period, the debt rollover plays a similar role as the exogenous expenditure $G_{1}$. That is, unless it chooses to default, the government has an obligation fixed in units of the consumption good to meet in the middle period. This implies that the amount of new debt the government must issue is endogenous and inversely related to the price of its debt, $q_{1}$.

\footnotetext{
${ }^{24}$ In contrast to the previous discussion, here the government has committed to no bailout as distinct from expected not to bailout.
} 
Second, allowing rollover does, of course, create yet another source of multiplicity along the lines of Cole and Kehoe (2000). Pessimistic investors might be unwilling to pay very much for the newly issued government debt in period 1, anticipating likely default in period 2. Since the newly issued debt, following the timing in Cole and Kehoe (2000), would be used to subsequently repay the outstanding obligation, the government may default already in period 1 .

Such a 'shut-down' equilibrium $\left(q_{1}=0\right)$ exists also in our baseline model too but we purposefully chose not to focus on it. Our goal, in part, was to distinguish fragility in debt markets from actual default. As noted in the introduction, these are two very distinct events.

A number of our results continue to hold in this modified model. First, there is an optimistic equilibrium in which there is no default in either period. As in Proposition 1, if investors believe there will be no default in period 2 , then government debt will be rolled over at a price of $q_{1}^{*}=\frac{1}{R}$ and there will be no default.

Second, as in Proposition 5, if there is sufficient equity issued by banks, then households will obtain the first best banking contract and will be insured against strategic uncertainty. Nonetheless, sunspots may play a role in both the roll over of government debt and its valuation in period 1.

Constructing equilbria with roll over risk and actual default in period 1, as in Cole and Kehoe (2000), combined with a bailout is considerably more difficult. If a government defaults in period 1 because it cannot roll over its debt, then it can not borrow further to finance a transfer payment to its banks. In this case, the reduction in the value of government debt will immediately create bank failures. There is a crisis but no diabolic loop.

If there is pessimism in period 1 about period 2 repayment but the debt is rolled over and no default occurs in period 1 , then the refinancing of the maturing debt will be more expensive for the government. In such a situation, a version of Proposition 2 still holds and is summarized in:

Proposition 7. If Condition 1 holds and

1. either (i) the default cost, $\gamma$, is sufficiently small or (ii) the cost of resolving the banking system, $\psi$, is sufficiently large, there will exist a SPNE with a government long term debt buyback at a price of $q_{1}^{T}=\frac{1}{R}$ in the pessimistic sunspot state. The first best banking contract is offered to households supported by a bailout in the pessimistic state. No equity is issued by the bank.

2. the default cost, $\gamma$, is sufficiently large and the cost of resolving the banking system, $\psi$, is sufficiently small, there will not exist a SPNE with a government long term debt buyback at a price of $q_{1}^{T}=\frac{1}{R}$ in the pessimistic sunspot state.

Proof. See Appendix, Section 9.3.8.

The introduction of a rollover problem increases the government's vulnerability to multiple equilibria in the sovereign debt market because, as already discussed, the need to refinance debt 
plays the same role as additional government expenditure in the middle date. Long term debt will be bought by the banks at the early date since it is risky and therefore entitles the bank to a bailout subsidy in the equilibrium in which the government chooses to bailout the banks under pessimism.

Then all the analysis in our baseline case goes through. The government saves the banks as long as the costs from bank failure are sufficiently large and the costs from sovereign default are sufficiently small. Banks overinvest in long term government debt and issue no equity.

\subsection{Strategic Default}

In our model, the period 2 government default is non-strategic. If the government has the tax capacity to repay, it does, otherwise it defaults. This simplification allows us to focus on the key decision of the government: to bailout the banks or not. Consequently, the cost of default has no direct impact on the probability of default. But it does have an indirect impact through the incentives of the government to bailout the banks. A forward looking government realizes that bailing out the banks increases the probability of default and thus of bearing the cost of $\gamma \bar{A}$. Hence, for us, bailout rather than default is the key strategic choice faced by the government.

Introducing strategic default into our framework is possible and does not change the essence of our results. To do this, we make three modifications to the model 25 First, investors have a labor supply choice in the last period. Second, there is distortionary taxation of this labor income. Third, there is a stochastic endowment element of the income of investors. This will suffer losses in the event of sovereign default. ${ }^{26}$

Taken together, this structure implies that paying off the debt is costly due to the distortionary taxation needed to finance the debt repayment. Since the labor endowment is random (and default costs are proportional to it), default is optimal only when the endowment is sufficiently low relative to the debt burden. And, most importantly, increases in debt outstanding will imply that default is more likely.

From the proof of Proposition 2, specifically (A.38) and (A.39), the default decision only impacts social welfare through the damage it causes to the endowment of investors. To see why, recall that banks sell their bonds to investors in the middle date. This is due to the fact that investors are risk-neutral while households (who deposit in banks) are risk averse and therefore it is optimal for investors to bear all the sovereign default risk. This implies that in period 2, households are insulated from the impact of default and only investors are affected. Hence any strategic default decision will be taken purely due to its impact on the welfare of investors.

\footnotetext{
${ }^{25}$ These are taken, in part, from Cooper, Kempf, and Peled (2008). As in that discussion, we assume the economy operates on the upper slope of the Laffer curve so that $\tau n(\tau)$ is increasing in $\tau$.

${ }^{26}$ It is also possible to consider a pure production economy with stochastic productivity that suffers in the event of default. This proved harder to obtain analytical results with. As this is not the baseline version of our model, we make the simplifying assumption that investors' income contains an endogenous element that is produced using labor and an exogenous endowment element which suffers in the event of default.
} 
Allowing for a labor supply choice, denoted $n$, and random endowment, denoted $\bar{A}$, the utility of the investor, conditional on repayment at the last date is given by:

$$
W_{2}^{I}=\bar{A}+(1-\tau) n-\frac{n^{1+\sigma}}{1+\sigma}+B_{1}
$$

where $B_{1}$ is the holding of debt by investors ${ }^{27}$ Let $n(\tau)$ be the utility maximizing level of work by an investor facing tax rate $\tau$. Then the net flow of utility from the employment choice is given by.

$$
Z(\tau)=(1-\tau) n(\tau)-\frac{n(\tau)^{1+\sigma}}{1+\sigma}
$$

The welfare of investors when the debt is repaid is given by:

$$
W^{r}=\bar{A}+Z(\tau)+B_{1}
$$

In this case investors pay taxes at a rate $\tau$ to finance the repayment of the debt obligation $B_{1}$. From the government budget constraint, the tax rate is determined by $\tau n(\tau)=B_{1}$.

The welfare of investors when the debt is not paid is given by:

$$
W^{d}=\bar{A}(1-\gamma)+Z(0)
$$

where $\gamma$ parameterizes the lost endowment under default. In this case, of course, the distortionary tax is set to zero.

Reducing the distortionary tax is the gain to default while $\gamma>0$ parameterizes the cost. Let $\Delta\left(\bar{A}, B_{1}\right) \equiv W^{r}-W^{d}$, so that

$$
\Delta\left(\bar{A}, B_{1}\right)=\gamma \bar{A}+Z(\tau)+B_{1}-Z(0)
$$

Clearly $\Delta\left(\bar{A}, B_{1}\right)$ is increasing in $\bar{A}$. To see that it is decreasing in $B_{1}$ : take a derivative of $Z(\tau)+B_{1}$ with respect to $B_{1}$ to obtain: $\frac{d\left(Z(\tau)+B_{1}\right)}{d B_{1}}=1+Z^{\prime}(\tau) \frac{d \tau}{d B_{1}}=1-\frac{n}{n+\tau n^{\prime}(\tau)}<0$. The sign uses that fact that the the denominator is positive when the economy operates on the upward sloping part of the Laffer curve.

The fact that $\Delta\left(\bar{A}, B_{1}\right)$ is increasing in $B_{1}$ is key to linking the endogenous default choice with the model of random tax capacity specified in Section 2.4.2. The property that default is more likely when debt outstanding is large is clearly robust to allowing endogenous default. This property is, of course, necessary for the existence of the diabolic loop.

\subsection{The Coexistence of Debt and Banking Fragility}

The existence of the diabolic loop has been illustrated based upon an initial bout of pessimism in debt markets. Yet the banking sector, along the traditional lines of Diamond and Dybvig (1983),

\footnotetext{
${ }^{27}$ There are other sources of income of investors, shown in A.38 and A.39, that are omitted as they are not impacted by the default choice of the government.
} 
can also be a source of pessimism in the form of a bank run, spreading to the debt market through government support of banks. This section illustrates this dimension of the diabolic loop and highlights the interaction of debt fragility and bank runs ${ }^{28}$ In fact, we find that an equilibrium with bank runs does not exist in our environment, even if the banking contract ignores the possibility of runs occurring.

We consider an environment with several key features. Specifically, we assume a Diamond and Dybvig (1983) style bank: (i) the banking contract is not contingent on the sunspot determining depositors' choice to withdraw or not and (ii) in the event a bank fails, it is unable to borrow against its illiquid investment. Thus the contract is a simplified version of that studied in section 2.2 with the restriction that the terms of the contract are independent of any sunspot. Further, for this analysis we again assume $G_{1}=0$ to highlight the role of government bailouts in the diabolic loop.

We show that bank runs will not exist because either the government will support the banks or (if a full bailout is infeasible or undesirable) banks will self insure. If a full bailout is feasible, we know from Proposition 2 that the government will choose to provide it under some conditions, thus destroying the conditions for a bank run. In Proposition 3 we have shown that when a full bailout is not feasible, banks will issue equity up to the point where the combined loss absorbency from equity buffers and state bailout funds are able to insure depositors fully. This again will destroy the conditions for the existence of a bank run.

Proposition 8. There is no SPNE with bank runs.

Proof. See Appendix, Section 9.3.9

This proposition assumed a Diamond-Dybvig style bank. Given that a bank run is offset either by government support or the provision ex ante of sufficient liquidity through equity, a bank run does not occur in equilibrium. This rationalizes the simple Diamond-Dybvig contract.

\section{Conclusions}

This paper builds a model of the feedback loop between banks and sovereigns. From Diamond and Dybvig (1983) and Calvo (1988), banks as well as sovereign debt markets are individually subject to powerful sources of strategic uncertainty, which can lead to multiple Pareto-ranked equilibria. Our paper characterizes a 'diabolic loop' that links these markets and thus propagates and amplifies the impact of strategic uncertainty emanating from debt markets.

Bank solvency is affected by sovereign bond market turmoil because the financial system holds a large amount of (largely domestic) government debt. In turn, government solvency is affected due

\footnotetext{
${ }^{28}$ The interaction of strategic uncertainty in sovereign debt and banking markets has been investigated by Leonello (2014) within a global games framework.
} 
to the implicit or explicit guarantees extended by governments to their banking systems. These interactions amplify the impact of pessimism in the government debt market. The initial decline in government debt prices reduces bank solvency and causes the implicit government promises to its banks to turn into explicit debt issuance at precisely the time when the government is least able to issue debt on favorable conditions. The higher debt issuance then pushes government debt prices even lower, completing the diabolic loop which has been rocking a number of European economies since 2010. The impact of these feedbacks is to make sovereign-banking crises much more severe than they otherwise would have been.

While we emphasize the effects of strategic uncertainty in debt markets as the initial shock, the model is general enough to accommodate other sources and types of uncertainty. As is well understood, the Diamond and Dybvig (1983) model often has a bank run equilibrium which itself could influence debt valuation through the cost of a government fulfilling obligations to banks. In fact, in our model no such equilibrium exists: either the government provides a bailout or the banks self-insure through equity. Moreover, fundamental shocks to either the banking system or the government fiscal situation would be magnified and propagated through the mechanisms identified in our model.

Having built a model of the crisis, we can consider a number of simple remedies for cutting the diabolic loop. One often suggested policy is just to let the banking system fail, imposing losses on depositors. Such a policy, if credible, would have multiple benefits. First, it would reduce the need for bailout assistance to add to government debt during a sovereign crisis. This, taken in isolation, would diminish the crisis amplification mechanisms we study in our paper. Second, when banks know they will not be bailed out, they will issue equity which will absorb losses from sovereign bond holdings without needing government assistance. Hence, bank solvency becomes completely decoupled from government solvency, severing a key linkage that has amplified the financial crisis in a number of EU countries.

The problem with such a commitment to let the banking system fail is that it is not credible. Governments, acting with discretion after a crisis, prefer (under some plausible conditions) to bailout the banking system rather than incur the deadweight losses associated with bank failure.

In turn, banks, anticipating that government assistance will be provided, have little incentive to issue equity. To the benefit of depositors, they take advantage of the 'heads-I-win, tails-you-lose' nature of the financial safety net. If the economy finds itself in an optimistic equilibrium, banks profit from high ex post bond returns. When the economy finds itself in the pessimistic equilibrium, the bank expects the government to bail it out in order to protect household deposits. This strategy extracts a transfer from taxpayers to bank depositors which makes the latter better off. As a result, banks rationally prefer to remain exposed to a sovereign debt crisis.

This moral hazard by banks might be corrected by regulatory interventions which impose capital requirements on banks' sovereign debt holdings until they become insulated from shocks in the debt market. In the light of this finding, it is puzzling that the new Basel III regime continues to favor 
domestic government debt over other assets by assigning it a zero capital weight. Moreover, domestic government debt continues to be exempt from large exposure limits creating exactly the kinds of incentives for banks to become overexposed to it described in our paper.

In our paper, capital requirements on sovereign exposures implement the first best allocation. Holding large equity buffers is not costly and insulates banks from strategic uncertainty in the sovereign debt market without distorting the banking contract. The only reason it is not privately implemented is due to moral hazard. In reality, of course, large capital buffers may come with their own costs such as higher tax costs or weaker incentives (as discussed in Mendicino, Nikolov, and Suarez (2016)). While beyond the scope of this paper, adding a richer analysis of government capital regulation seems to us like a interesting avenue for future research.

Future work will analyze the international dimension of the European twin crisis. Financial stability policy in Europe is undergoing major reform with the establishment of the Single Supervisory Mechanism (SSM) and with the use of Outright Monetary Transactions (OMT) by the European Central Bank. We intend to embed our single country model into a multi-country setting and consider the union-wide policies which can limit the economic damage done by the 'diabolic loop'.

Finally, the role of fiscal policy in the diabolic loop deserves additional emphasis. Our model assumes that bailouts must be financed by new debt issuances. If instead, bailouts were offset by a reduction in government spending or an increase in taxation, then the loop would be broken. In addition, maintaining very healthy public finances so as to be able to bail banks out in a crisis without increasing sovereign default risk would also break the co-dependence of banks and their governments 29 Of course, these options have their own costs which must be taken into account.

\section{Online Appendix}

This is intended as an online appendix.

\subsection{Banking Problem}

The bank solves:

$$
\max _{i_{0}, B_{0}^{B}, x_{0}, c^{E}(s), c^{L}\left(s, \mathbb{1}_{G}\right), \delta_{2}\left(s, \mathbb{1}_{G}\right), l_{1}(s), B_{1}^{B}(s), L_{1}(s)} E\left[\pi u\left(c^{E}(s)\right)+(1-\pi) u\left(c^{L}\left(s, \mathbb{1}_{G}\right)\right)\right]
$$

such that

$$
\begin{gathered}
i_{0}+q_{0} B_{0}^{B} \leq d+x_{0} \\
\pi c^{E}(s) \leq q_{1}(s)\left(B_{0}^{B}-B_{1}^{B}(s)\right)+\varepsilon l_{1}(s)-L_{1}(s)+T\left(q_{1}(s), B_{0}^{B}\right), \forall s \\
(1-\pi) c^{L}\left(s, \mathbb{1}_{G}\right) \leq\left(1-\mathbb{1}_{G}\right) B_{1}^{B}(s)+R\left(i_{0}-l_{1}(s)\right)-\delta_{2}\left(s, \mathbb{1}_{G}\right)-r^{b}(s) L_{1}(s), \forall s \\
E \delta_{2}\left(s, \mathbb{1}_{G}\right) \geq R x_{0}
\end{gathered}
$$

\footnotetext{
${ }^{29}$ These types of fiscal buffers were suggested by a referee.
} 


$$
E u\left(c^{L}\left(s, \mathbb{1}_{G}\right)\right) \geq u\left(\beta c^{E}(s)\right) ; E u\left(c^{E}(s)\right) \geq u\left(\beta c^{L}\left(s, \mathbb{1}_{G}\right)\right) \forall s
$$

In what follows, we treat the two IC constraints in A.6 as non-binding and check that the banking contract we solve for satisfies them. The first order conditions to the contracting problem in A.1 with respect to $\left(c^{E}(s), c^{L}\left(s, \mathbb{1}_{G}\right), B_{0}^{B}, i_{0}, x_{0}, \delta_{2}\left(s, \mathbb{1}_{G}\right), l_{1}(s), B_{1}^{B}(s), L_{1}(s)\right)$ are:

$$
\begin{gathered}
\nu(s) u^{\prime}\left(c^{E}(s)\right)-\lambda^{E}(s)=0 \\
p(s) \nu(s) u^{\prime}\left(c^{L}\left(s, \mathbb{1}_{G}=0\right)\right)-\lambda^{L}\left(s, \mathbb{1}_{G}=0\right)=0 \\
(1-p(s)) \nu(s) u^{\prime}\left(c^{L}\left(s, \mathbb{1}_{G}=1\right)\right)-\lambda^{L}\left(s, \mathbb{1}_{G}=1\right)=0 \\
q_{0} \phi=\sum_{s}\left[q_{1}(s)+T_{B}\left(q_{1}(s), B_{0}^{B}\right)\right] \lambda^{E}(s) \\
\phi=R \sum_{s, \mathbb{1}_{G}} \lambda^{L}\left(s, \mathbb{1}_{G}\right) \\
(\phi-R \chi) x_{0}=0 \\
\left(p(s) \nu(s) \chi-\lambda^{L}\left(s, \mathbb{1}_{G}=0\right)\right) \delta_{2}\left(s, \mathbb{1}_{G}=0\right)=0 \\
\left((1-p(s)) \nu(s) \chi-\lambda^{L}\left(s, \mathbb{1}_{G}=1\right)\right) \delta_{2}\left(s, \mathbb{1}_{G}=1\right)=0 \\
\left(\varepsilon \lambda^{E}(s)-R \sum_{\mathbb{1}_{G}} \lambda^{L}\left(s, \mathbb{1}_{G}\right)\right) l_{1}(s)=0 . \\
\left(\lambda^{E}(s) q_{1}(s)-\lambda^{L}\left(s, \mathbb{1}_{G}\right)\right) B_{1}^{B}(s)=0 . \\
\left(\lambda^{E}(s)-r^{b}(s) \sum_{\mathbb{1}_{G}} \lambda^{L}\left(s, \mathbb{1}_{G}\right)\right) L_{1}(s)=0
\end{gathered}
$$

where $\nu(s)$ is the probability of state $s, \phi$ is the multiplier on $(\mathrm{A} .2), \lambda^{E}(s)$ is the multiplier on A.3),$\left.\lambda^{L}\left(s, \mathbb{1}_{G}\right)\right)$ is the multiplier on (A.4), for all $s$ and default choices, and $\chi$ is the multiplier on A.5). Here, $p(s)$ is the probability of sovereign debt repayment in period 2 when the sunspot state in period 1 was $s$. These necessary conditions will be used in the subsequent proofs.

When the government supports the banking system through a buyback at target price $q_{1}^{T}$, the bailout transfer for each is given by:

$$
T\left(q_{1}(s), B_{0}^{B}\right)=\left(q_{1}^{T}-q_{1}(s)\right) B_{0}^{B}
$$

Hence the bank's budget constraint in period becomes

$$
\pi c^{E}(s) \leq q_{1}^{T}\left(B_{0}^{B}-B_{1}^{B}(s)\right)+\varepsilon l_{1}(s)-L_{1}(s), \forall s
$$

Due to the government buyback scheme, the bank is able to sell its bonds not at the market price $q_{1}(s)$ but at the target price $q_{1}^{T}$. In the proofs that follow we use this specification of the bank's period 1 budget constraint. 


\subsection{Bank Resolution Mechanism}

Assume that the government does not bailout the banks. For the bailout equilibria we construct, this is off the equilibrium path as the banks had anticipated a bailout. Yet understanding what happens in this case is necessary for constructing an equilibrium.

If there is no bailout, the banks are insolvent and the banking system is shut down. At this point, the banks re-optimize given their existing assets and liabilities without government involvement. This re-optimization occurs with a cost $\psi$ which is proportional to the size of the bank's balance sheet. This is a standard bankruptcy cost. The bankruptcy cost comes out of liquid assets but this is not important due to the presence of the interbank market which allows the bank to borrow against the value of the long term technology if the payment of the bankruptcy cost creates a shortage of liquidity in period 1 . The bank solves the following problem:

$$
\begin{aligned}
& \max _{c^{E}, c^{L}\left(\mathbb{1}_{G}\right), B_{1}^{B} \geq 0, L_{1}} \pi u\left(c^{E}\right)+(1-\pi)\left[p^{N B} u\left(c^{L}\left(\mathbb{1}_{G}=0\right)\right)+\left(1-p^{N B}\right) u\left(c^{L}\left(\mathbb{1}_{G}=1\right)\right)\right] \\
& +\lambda^{E}\left(q_{1}^{N B}\left(B_{0}^{B}-B_{1}^{B}\right)-\psi d+L_{1}-\pi c^{E}\right) \\
& +\lambda^{L}\left(\mathbb{1}_{G}=0\right)\left(R\left(i_{0}-L_{1}\right)+B_{1}^{B}-(1-\pi) c^{L}\left(\mathbb{1}_{G}=0\right)\right) \\
& +\lambda^{L}\left(\mathbb{1}_{G}=1\right)\left(R\left(i_{0}-L_{1}\right)-(1-\pi) c^{L}\left(\mathbb{1}_{G}=1\right)\right)
\end{aligned}
$$

In these expressions, $\mathbb{1}_{G}=0$ is a state of debt repayment by the government and $\mathbb{1}_{G}=1$ denotes default. The probability of repayment is $p^{N B}$. Here the bank chooses the consumption levels of the two types of households, with the consumption of late households contingent on the government default decision in the next period. The bank can sell debt to finance the consumption of early households, $\left(B_{0}^{B}-B_{1}^{B}\right)$, as well as borrow from investors in period $1, L_{1}$. While the bank could also liquidate the illiquid investment, this is dominated by borrowing from investors at an interest rate of $R$, the marginal rate of substitution for investors, and is not considered. We establish later that this is the equilibrium rate in the interbank market i.e. $r^{b}=R$.

In the optimization problem of the bank, A.19, the price of debt, $q_{1}^{N B}$, is taken as given as individual banks are small. Further, there is no fiscal operation associated with the bank resolution. The first order conditions are:

$$
\begin{gathered}
u^{\prime}\left(c^{E}\right)-\lambda^{E}=0 \\
p^{N B} u^{\prime}\left(c^{L}\left(\mathbb{1}_{G}=0\right)\right)-\lambda^{L}\left(\mathbb{1}_{G}=0\right)=0 \\
\left(1-p^{N B}\right) u^{\prime}\left(c^{L}\left(\mathbb{1}_{G}=1\right)\right)-\lambda^{L}\left(\mathbb{1}_{G}=1\right)=0 \\
\left(-q_{1}^{N B} \lambda^{E}+\lambda^{L}\left(\mathbb{1}_{G}=0\right)\right) B_{1}^{B}=0 \\
\lambda^{E}-R \sum_{\mathbb{1}_{G}} \lambda^{L}\left(\mathbb{1}_{G}\right)=0
\end{gathered}
$$

Let $\hat{c}^{E}$ and $\hat{c}^{L}\left(\mathbb{1}_{G}\right)$ denote the optimal consumption allocations when the bank gets 'resolved' in this manner. Substituting A.24 into A.23, implies: 


$$
\left(\lambda^{L}\left(\mathbb{1}_{G}=0\right)\left(1-R q_{1}^{N B}\right)-R q_{1}^{N B} \lambda^{L}\left(\mathbb{1}_{G}=1\right)\right) B_{1}^{B}=0 .
$$

Since $q_{1}^{N B}=p^{N B} / R$, this implies that:

$$
\left(\lambda^{L}\left(\mathbb{1}_{G}=0\right)\left(1-p^{N B}\right)-p^{N B} \lambda^{L}\left(\mathbb{1}_{G}=1\right)\right) B_{1}^{B}=0 .
$$

Using A.21 and A.22, we get:

$$
\left(u^{\prime}\left(c^{L}\left(\mathbb{1}_{G}=0\right)\right)-u^{\prime}\left(c^{L}\left(\mathbb{1}_{G}=1\right)\right)\right) B_{1}^{B}=0 .
$$

As long as $B_{1}^{B}>0$, households suffer losses when the government defaults and $u^{\prime}\left(c^{L}\left(\mathbb{1}_{G}=0\right)\right)-$ $u^{\prime}\left(c^{L}\left(\mathbb{1}_{G}=1\right)\right)<0$. Thus for A.25 to hold, $B_{1}^{B}=0$.

When $B_{1}^{B}=0$, the resources to finance late consumption are independent of government default, $\hat{c}^{L}\left(\mathbb{1}_{G}=0\right)=\hat{c}^{L}\left(\mathbb{1}_{G}=1\right)$. From the first three first-order conditions and (A.24):

$$
u^{\prime}\left(\hat{c}^{E}\right)=R u^{\prime}\left(\hat{c}^{L}\right)
$$

Thus the marginal rate of substitution is the same without bailout as it is with bailout. But the solution to the problem without bailout must generate lower welfare to depositors than the optimistic outcome since $q_{1}^{N B}<\frac{1}{R}$.

If utility is concave and if $\beta$ is sufficiently small, the resulting allocations are incentive compatible in the sense that the IC constraints A.6 are satisfied.

Finally the net present value of the re-negotiated consumption promises to depositors in the resolved bank satisfies:

$$
\pi \hat{c}^{E}+\frac{(1-\pi) \hat{c}^{L}}{R}=q_{1}^{N B} B_{0}^{B}-\psi d+\frac{i_{0}}{R} .
$$

Comparing A.29 with the net present value of consumption allocations under the optimistic equilibrium, we can see that the difference arises due to two factors.

$$
\pi\left(c^{* E}-\hat{c}^{E}\right)+\frac{(1-\pi)\left(c^{* L}-\hat{c}^{L}\right)}{R}=\left(\frac{1}{R}-q_{1}^{N B}\right) B_{0}^{B}+\psi d,
$$

These are the loss of wealth due to the decline in the government bond price as well as the resolution cost $\psi d$.

\subsection{Proofs}

\subsubsection{Proof of Lemma 1}

Lemma 1. In the optimal banking contract with no default risk and $q_{0}=q_{1}=\frac{1}{R}$ : (i) $c^{L}>c^{E}$ (ii) $l_{1}=0$ and (iii) $x_{0}=0$. 
Proof. With $q_{1}(s)=\frac{1}{R}$, no sunspots and no default, the first-order conditions for the optimal contract become:

$$
\begin{gathered}
u^{\prime}\left(c^{E}\right)-\lambda^{E}=0 \\
u^{\prime}\left(c^{L}\right)-\lambda^{L}=0 \\
q_{0} \phi=\frac{\lambda^{E}}{R} \\
\phi=R \lambda^{L} \\
\left(\varepsilon \lambda^{E}-R \lambda^{L}\right) l_{1}=0 .
\end{gathered}
$$

Using $q_{0}=\frac{1}{R}$, combining A.33 and A.34 implies $\phi=\lambda^{E}=R \lambda^{L}$. Substituting this into A.31 and A.32 implies

$$
u^{\prime}\left(c^{E}\right)=R u^{\prime}\left(c^{L}\right) .
$$

This condition implies property (i): $c^{L}>c^{E}$ for all $R>1$ as $u(\cdot)$ is strictly concave. Hence late consumers prefer their own allocation to that of early consumers. In addition, if $\beta$ is sufficiently small, early consumers will prefer their own allocation to that of lates. Hence A.35 is satisfied. Using A.35, $l_{1}$ is zero, and strictly so if $\varepsilon<1$, as $\lambda^{E}=R \lambda^{L}$. Finally, because there is no uncertainty facing the bank, there is no need to issue equity. Hence $x_{0}=0$.

\subsubsection{Proof of Proposition 1}

Proposition 1. There exists an optimistic rational expectations equilibrium with $q_{0}^{*}=q_{1}^{*}=\frac{1}{R}$, $r^{b}=R$ and the banking contract given by $\left(c^{* E}, c^{* L}\right)$.

Proof. The equilibrium conditions are driven by the investors. We assume that the aggregate endowment of the investors is larger than the stock of government debt in period 0 . The investors can either put their endowment directly in the illiquid technology and obtain $R$ or purchase two period government debt. They are indifferent between these options if $q_{0}=\frac{1}{R}$. If this condition holds, they are willing to purchase any of the government debt not held by the banking system. Since investors have linear utility of $c_{1}+\frac{1}{R} c_{2}$, they are indifferent between consuming their period 1 endowment and buying one period government debt if $q_{1}=\frac{1}{R}$. Assuming that investors' period 1 endowment is sufficiently large, if $q_{1}=\frac{1}{R}$, the investors will purchase the debt sold by the banks in period 1 and the new debt issued by the government in period 1 .

Thus, at these prices, all markets clear. The excess supply of government debt in period 0 is purchased by the investors. The stock of government debt held by bank is sold to the investors along with any new debt in period 1. The market for government debt clears in both periods. Given that $q_{0}^{*}=q_{1}^{*}=\frac{1}{R}$, the probability of government default is zero. 
Further, at $r^{b}=R$, investors are indifferent both with respect to the timing of their consumption and the composition of their portfolio. This indifference guarantees market clearing in the interbank market at zero trade.

The result that the first best contract is provided in equilibrium comes from Proposition 1. In equilibrium, banks will hold enough debt to finance their payment to early consumers at the anticipated period 1 price: $b_{0} q_{1}=\pi c^{* E}$. The debt is sold to the investors for goods and those goods are transferred to the early consumers. There are no liquidations in an optimistic equilibrium.

\subsubsection{Proof of Proposition 2}

Proposition 2. If Condition 1 holds and

1. either (i) the default cost, $\gamma$, is sufficiently small or (ii) the cost of resolving the banking system, $\psi$, is sufficiently large, there will exist a SPNE with a government debt buyback at a price of $q_{1}^{T}=\frac{1}{R}$ in the pessimistic sunspot state. The first best banking contract is offered to households supported by a bailout in the pessimistic state. No equity is issued by the bank.

2. the default cost, $\gamma$, is sufficiently large and the cost of resolving the banking system, $\psi$, is sufficiently small, there will not exist a SPNE with a government debt buyback at a price of $q_{1}^{T}=\frac{1}{R}$ in the pessimistic sunspot state.

Proof. The proof has three steps: (i) characterizing the optimal banking contract, (ii) determining the government's bailout choice and (iii) checking market clearing.

\section{Step 1: Optimal Contract}

To construct an equilibrium, suppose the banks anticipate a bailout by the government in the event of pessimism. The banking contract with expected bailouts solves (A.1) with the resource constraint for early consumers in the pessimistic state modified to reflect the government debt buyback program:

$$
\pi c^{E}\left(s^{p}\right) \leq \frac{1}{R}\left(B_{0}^{B}-B_{1}^{B}\left(s^{p}\right)\right)+\varepsilon l_{1}\left(s^{p}\right)-L_{1}\left(s^{p}\right)
$$

Here the government buys government bonds from the banks at the optimistic price of $q_{1}\left(s^{p}\right)=\frac{1}{R}$, making the return on government bonds independent of the sunspot. This is the form of anticipated government support in the pessimistic sunspot state.

The government debt support at $\frac{1}{R}$ implies that the contract between the bank and the households is immune from the sunspot. With $q_{0}=\frac{1}{R}$, verified below, the bank problem is identical to that solved in the optimistic equilibrium, characterized in Proposition 1. Hence the banking contract is the first best one, $\left(c^{* E}, c^{* L}\right)$, which, as noted above, is incentive compatible.

Given that the households are insured through the government buyback, there is no gain to supplying equity to the bank. Hence $x_{0}=0$. 


\section{Step 2: Government's Choice}

The government will choose between a buyback, denoted $B B$, and no bailout, denoted $N B$. Under a buyback scheme, the government will buy as much debt as banks supply at a price denoted $q_{1}^{T}=\frac{1}{R}$. Throughout, let $\left(\mathbb{1}_{G}=0\right)$ denote the states in which the government repays its debt and let $\left(\mathbb{1}_{G}=1\right)$ denote default states. Given that the government debt market is in a state of pessimism, the analysis characterizes the payoffs in periods 1 and 2 to households and investors with and without a debt buyback.

\section{Welfare under Full Bailout}

First, suppose that the government supports the banks by purchasing debt at a price $q_{1}^{T}$. This transfer is financed through the issuance of new debt.

\section{Investors}

If a debt buyback is provided, at the middle date investors consume the difference between their endowment, the bonds they buy from banks $B_{0}^{B}$ and the amount they lend to banks $L_{1}{ }^{30}$

$$
c_{1}^{I, B B}=A_{1}-q_{1}^{B B}\left(B_{0}^{B}+\left(T\left(q_{1}^{B B}\right)\right) / q_{1}^{B B}\right)-L_{1} .
$$

At the final date, investors consume all their net worth. Their consumption depends on the default decision of the government.

If the government repays its debt, consumption is given by:

$$
\begin{aligned}
c_{2}^{I, B B}\left(\mathbb{1}_{G}=0\right) & =\bar{A}+B_{1}+R i_{0}^{I}+R L_{1}-\tau \bar{A} . \\
& =\bar{A}+R i_{0}^{I}+R L_{1} .
\end{aligned}
$$

where the second equality follows from the fact that the banking system sells its entire holding of government debt in the pessimistic equilibrium. Hence investors own all debt and pay the taxes to pay the debt obligation. The two cancel out $\left(B_{1}=\tau \bar{A}\right)$.

If the government defaults, investors' final period consumption is given by:

$$
c_{2}^{I, B B}\left(\mathbb{1}_{G}=1\right)=\bar{A}(1-\gamma)+R i_{0}^{I}+R L_{1} .
$$

Investors' welfare is affected by the default decision, in part, due to the output costs of default assumed in our specification of the final date endowment. Investors' expected welfare is:

$$
W^{I, B B}=c_{1}^{I, B B}+E\left[\frac{1}{R} c_{2}^{I, B B}\left(\mathbb{1}_{G}\right)\right]
$$

where the expectation is over the government default decision in period 2 .

\section{Depositors}

The utility of depositors when the government buys back debt is independent of its decision to default and is given by the utility delivered by the standard banking contract

$$
W^{H, B B}=\pi u\left(c^{* E}\right)+(1-\pi) u\left(c^{* L}\right)
$$

\footnotetext{
${ }^{30}$ In the pessimistic equilibrium, banks sell their entire holdings of government debt $\left(B_{0}^{B}\right)$ to investors in the middle period.
} 


\section{Welfare if a buyback is provided}

Social welfare when a buyback is provided is:

$$
\begin{aligned}
& W^{B B}=\pi u\left(c^{E}\right)+(1-\pi) u\left(c^{L}\right) \\
&+\omega\left[A_{1}-q_{1}^{B B}\left(B_{0}^{B}+\left(T\left(q_{1}^{B B}\right)\right) / q_{1}^{B B}\right)\right]+\frac{\omega}{R}\left(\bar{A}+R i_{0}^{I}\right)-\frac{\omega}{R}\left(1-p^{B B}\right) \gamma \bar{A} .
\end{aligned}
$$

With a buyback price of $\frac{1}{R}, T\left(q_{1}^{B B}\right)=B_{0}^{B}\left(\frac{1}{R}-q^{B B}\right)$. Thus $q_{1}^{B B}\left(B_{0}^{B}+T\left(q_{1}^{B B}\right) / q_{1}^{B B}\right)=\frac{B_{0}^{B}}{R}$ so that investor consumption in period 1 is simply $A_{1}-\frac{B_{0}^{B}}{R}$.

In A.40, $p^{B B}$ is the probability that the government repays at the final date conditional upon a buyback being provided:

$$
p^{B B}=1-F\left(\frac{B_{0}+T\left(q_{1}^{B B}\right) / q_{1}^{B B}}{\bar{A}}\right) .
$$

In $\mathrm{A} .40, q_{1}^{B B}$ denotes the price of government debt in the middle period if there is pessimism and a bailout is provided. This is determined from the investor's arbitrage condition of $\frac{p^{B B}}{q_{1}^{B B}}=R$ and A.41). Finding the $\left(p^{B B}, q_{1}^{B B}\right)$ that solves these two conditions is the same as finding a solution to (13), other than the optimistic equilibrium. By assumption, the economy is in a pessimistic solution to 13 .

\section{Welfare without a Bailout}

Welfare if no buyback is provided When no buyback is provided (when one had been anticipated), the banking system is insolvent and the government steps in to resolve the failing financial institutions. Full discussion of the bank resolution mechanism can be found in section 9.2. Here we merely make use of the outcomes of the bank resolution mechanism to compute social welfare when no buyback is provided:

$$
\begin{array}{rrr}
W^{N B} & = & \pi u\left(\hat{c}^{E}\right)+(1-\pi) u\left(\hat{c}^{L}\right) \\
& + & \omega\left[A_{1}-q_{1}^{N B}\left(B_{0}^{B}\right)\right]+\frac{\omega}{R}\left(\bar{A}+R i_{0}^{I}\right) .
\end{array}
$$

In these expressions, the loans to banks made by the investors in period 1 cancel with the proceeds from those loans at the interbank loan rate of $r^{b}=R$.

The probability that the government repays its debt $\left(p^{N B}\right)$ is equal to unity since no additional funds are raised from the market. This is why the above expression for social welfare does not depend on the deadweight losses from sovereign default.

The Bailout Decision

The difference in the value of the social welfare function between bailout and no bailout is: 


$$
\begin{aligned}
\Delta & \equiv W^{B B}-W^{N B} \\
& =\pi\left[u\left(c^{* E}\right)-u\left(\hat{c}^{E}\right)\right]+(1-\pi)\left[u\left(c^{* L}\right)-u\left(\hat{c}^{L}\right)\right]-\omega\left(\frac{1}{R}-q_{1}^{N B}\right) B_{0}^{B} \\
& +\frac{\omega}{R}\left(p^{B B}-1\right) \gamma \bar{A} .
\end{aligned}
$$

where $p^{N B}=1$ and $p^{B B}$ is given by A.41.

From our analysis of the bank resolution mechanism in section $(9.2)$, we know that the difference in the net present value of consumption promises under the optimistic contract and the bank resolution allocation is given by A.30. Hence:

$$
\omega\left(\frac{1}{R}-q_{1}^{N B}\right) B_{0}^{B}=\omega\left(\pi\left[c^{* E}-\hat{c}^{E}\right]+(1-\pi)\left[\frac{c^{* L}-\hat{c}^{L}}{R}\right]-\psi d\right) .
$$

Using $\omega=u^{\prime}\left(c^{* E}\right)=R u^{\prime}\left(c^{* L}\right)$, the first term in A.43 becomes

$$
\begin{aligned}
& \pi\left[u\left(c^{* E}\right)-u\left(\hat{c}^{E}\right)\right]+(1-\pi)\left[u\left(c^{* L}\right)-u\left(\hat{c}^{L}\right)\right]- \\
& u^{\prime}\left(c^{* E}\right)\left(\pi\left[c^{* E}-\hat{c}^{E}\right]+(1-\pi)\left[\frac{c^{* L}-\hat{c}^{L}}{R}\right]\right)+u^{\prime}\left(c^{* E}\right) \psi d
\end{aligned}
$$

By the strictly concavity of $u(\cdot)$ the first row of $\mathrm{A} .45$ is positive. This represents the insurance gain to redistribution through a debt buyback. The second row of A.45 represents the gains due to the avoidance of the deadweight costs of bank default. It is rising in the size of deadweight losses from bank default $\psi d$.

The second term in A.43 is proportional to the difference in the expected output costs of sovereign default due to the provision of a bailout relative to no bailout.

$$
\left(p^{B B}-1\right) \gamma \bar{A}
$$

This term is clearly negative because the probability of repayment in the pessimistic equilibrium under a bailout $\left(p^{B B}\right)$ is always lower than the (unit) probability of repayment when no bailout is provided $\left(p^{N B}\right)$. The term is rising in the size of deadweight losses from default $\gamma \bar{A}$.

$\Delta>0$ and a bailout is provided whenever $\gamma$ is sufficiently small and $\psi$ is sufficiently large. In that case, the gains from redistribution and from avoiding costly bank failures outweight the increase in the expected costs of the bailout.

If markets clear at the presumed prices, then we have a sufficient conditions for $\Delta>0$ and the provision of a bailout. Step 3 of the proof shows that markets clear at the conjectured prices.

\section{Step 3: Market Clearing}

We construct prices such that markets clear. All government debt is held by banks as they receive the benefits of the debt buyback. From Assumption 1, this is feasible because bank deposits are larger than the government debt stock at the initial date. 
At $q_{0}=\frac{1}{R}$, as assumed in the construction of the equilibrium, banks are indifferent between illiquid investment and the holding of government debt to finance the consumption of late households. The banks are the marginal holders of the government debt in period 0. Along the equilibrium path, banks sell all the risk debt to investors at date 1, i.e. $B_{1}^{B}=0$.

Period 1 prices are $q_{1}\left(s^{o}\right)=\frac{1}{R}$ and $q_{1}\left(s^{p}\right)=\frac{p^{B B}}{R}$ where $p^{B B}<1$ is the probability of repayment under bailout given by (A.41).

From the preferences of the investors, they are willing to lend as much as demanded in the interbank market if $r^{b}=R$. Thus this market will clear at that price with and without government debt buyback.

\subsubsection{Proof of Proposition 3}

Proposition 3. Suppose Condition 2 holds and the government lacks commitment. If

1. either (i) the default cost, $\gamma$, is sufficiently small or (ii) the cost of resolving the banking system, $\psi$, is sufficiently large, there will exist a SPNE with a government debt buyback at a price of $q_{1}^{\max }<\frac{1}{R}$ in the pessimistic sunspot state, where $q_{1}^{\max }$ is the maximum buyback price such that a pessimistic equilibrium exists. The first best banking contract is offered to households, supported by a combination of investor equity and a partial bailout in the pessimistic state.

2. the default cost, $\gamma$, is sufficiently large and the cost of resolving the banking system, $\psi$, is sufficiently small, there will not exist a SPNE with a government debt buyback at a price of $q_{1}^{\max }$ in the pessimistic sunspot state.

Proof. The proof has three steps: (i) characterizing the optimal banking contract, (ii) determining the government's bailout choice and (iii) checking market clearing.

\section{Step 1: Optimal Contract}

To construct an equilibrium when Condition 2 holds, suppose the banks anticipate the maximum feasible bailout by the government in the event of pessimism. Let $q_{1}^{\max }<q_{1}^{*}$ denote the maximum buyback price at which the government is able to repurchase the sovereign bonds in the event of pessimism. This maximum buyback price is given by the tangency point of the yellow debt valuation curve to the 45 degree line in Figure 2. A higher bailout price is not consistent with the existence of a pessimistic equilibrium.

The banking contract with expected bailouts solves A.1 with the resource constraint for early consumers in the pessimistic state modified to reflect the government debt buyback program:

$$
\pi c^{E}\left(s^{p}\right) \leq q_{1}^{\max }\left(B_{0}^{B}-B_{1}^{B}\left(s^{p}\right)\right)+\varepsilon l_{1}\left(s^{p}\right)-L_{1}\left(s^{p}\right)
$$

Unlike in Proposition 2, here the government does not fully insulate the bank from the risk in government bonds because this is infeasible. 
This leaves the bank with a choice of whether to expose depositors to risk or whether to insure them fully by issuing equity. From Proposition 4 we know that equity issuance implements the first best banking contract. This contract gives the highest utility to a depositor bringing $d$ units of deposits to the bank and, since it is feasible, the bank issues equity and offers this allocation to households. This allocation satisfies the IC constraints, A.6.

The bank issues equity $x_{0}$ such that it is just solvent under pessimism provided that the government does buy back the debt at price $q_{1}^{\max }$. For the bank to be solvent in the pessimistic state, the net present value of liabilities $\left(c^{* E}, c^{* L}\right)$ must be equal to the value of bank assets when a debt buyback is provided:

$$
i_{0}=\pi c^{* E}+\frac{(1-\pi) c^{* L}}{R}-q_{1}^{\max } B_{0}
$$

Hence, using the period 0 budget constraint:

$$
\begin{aligned}
x_{0}\left(q_{1}^{\max }\right) & =q_{0} B_{0}+i_{0}-d \\
& =\left(q_{0}-q_{1}^{\max }\right) B_{0}+\pi c^{* E}+\frac{(1-\pi) c^{* L}}{R}-d \\
& =\left(q_{0}-q_{1}^{\max }\right) B_{0}
\end{aligned}
$$

where the third equality follows from the fact that depositors receive claims whose net present value equals the funds they deposit in the bank. Equity is issued to protect the bank from potential losses on sovereign bond holdings. The lower the buyback price $q_{1}^{\max }$ relative to $q_{0}$ the more equity needs to be issued by the banks in order to protect their depositors from fluctuations in government bond values.

The bank has no incentive to issue more equity than this amount because it is insured by the government's buyback policy anyway. It will not want to issue less because, by the definition of $q_{1}^{\max }$ the government is unable (because Condition 1 does not hold) to offer a larger bailout.

\section{Step 2: Government's Choice}

The proof proceeds in a parallel fashion to the proof of Proposition 2. The government will choose between the partial buyback, denoted $P B$, and no bailout, denoted $N B$. Under a buyback scheme, the government will buy as much debt as banks supply at a price of $q_{1}^{\max }$. Throughout, let $\left(\mathbb{1}_{G}=0\right)$ denote the states in which the government repays its debt and let $\left(\mathbb{1}_{G}=1\right)$ denote default states. Given that the government debt market is in a state of pessimism, the analysis characterizes the payoffs in periods 1 and 2 to households and investors with and without a debt buyback.

\section{Welfare under the Partial Bailout}

First, we examine the case when the government acts as expected by purchasing debt at a price $q_{1}^{\max }$. This transfer is financed through the issuance of new debt. Following similar derivations as in Proposition 3 social welfare when a buyback is provided is:

$$
\begin{gathered}
W^{P B}=\pi u\left(c^{* E}\right)+(1-\pi) u\left(c^{* L}\right) \\
+\omega\left[A_{1}-q_{1}^{\max } B_{0}^{B}\right]+\frac{\omega}{R}\left(\bar{A}+R i_{0}^{I}\right)-\frac{\omega}{R}\left(1-p^{P B}\right) \gamma \bar{A} .
\end{gathered}
$$


In A.48, $p^{P B}$ is the probability that the government repays at the final date conditional upon a buyback at price $q_{1}^{\max }$ being provided:

$$
p^{P B}=1-F\left(\frac{B_{0}+T\left(q_{1}^{P B}\right) / q_{1}^{P B}}{\bar{A}}\right) .
$$

In A.49, $q_{1}^{P B}$ denotes the market price of government debt in the middle period if there is pessimism and a bailout is provided. This is determined from the investor's arbitrage condition of $\frac{p^{P B}}{q_{1}^{P B}}=R$ and A.49. Finding the $\left(p^{P B}, q_{1}^{P B}\right)$ that solves these two conditions is the same as finding a solution to (13), other than the optimistic equilibrium. By assumption, the economy is in a pessimistic solution to (13).

\section{Welfare without a Bailout}

When the government does not bailout the banks (as expected on the equilibrium path), they are insolvent. This triggers default costs up to the value of $\psi$ fraction of the bank's balance sheet $(\psi d)$. At this point, the banks re-optimize given their existing assets and liabilities without government involvement.

As shown in the proof to Proposition 2, the bank solves $($ A.19 with a solution which delivers $\hat{c}^{E}<c^{* E}$ and $\hat{c}^{L}<c^{* L}$ to depositors such that $u^{\prime}\left(\hat{c}^{E}\right)=R u^{\prime}\left(\hat{c}^{L}\right)$. The bank sells all its bonds to investors $\left(B_{1}^{B}=0\right)$ thus making the allocation to late investors independent of the sunspot shock. However all depositors receive a smaller allocation compared to the first best reflecting the decline in bank asset values as a result of the sunspot. The consumption allocation is increasing in the amount of equity issued by the bank at the initial date.

Welfare if no buyback is provided

Social welfare when no buyback is provided is:

$$
\begin{aligned}
& W^{N B}=\quad \pi u\left(\hat{c}^{E}\right)+(1-\pi) u\left(\hat{c}^{L}\right) \\
& +\quad \omega\left[A_{1}-q_{1}^{N B} B_{0}^{B}\right]+\frac{\omega}{R}\left(\bar{A}+R i_{0}^{I}\right) .
\end{aligned}
$$

In these expressions, the loans to banks made by the investors in period 1 cancel with the proceeds from those loans at the interbank loan rate of $r=R$.

When no buyback is provided $p^{N B}=1$ and the probability of sovereign default is zero. This is why the above expression does no depend on the deadweight costs of sovereign default $(\gamma)$.

The Bailout Decision

The difference in the value of the social welfare function between buyback and not is:

$$
\begin{aligned}
\Delta & \equiv W^{P B}-W^{N B} \\
& =\pi\left[u\left(c^{* E}\right)-u\left(\hat{c}^{E}\right)\right]+(1-\pi)\left[u\left(c^{* L}\right)-u\left(\hat{c}^{L}\right)\right]-\omega\left(q_{1}^{\max }-q_{1}^{N B}\right) B_{0}^{B} \\
& +\frac{\omega}{R}\left(p^{P B}-1\right) \gamma \bar{A} .
\end{aligned}
$$

where $p^{P B}$ is given by A.49. 
From the constraints of the banking problems,

$$
\pi\left[c^{* E}-\hat{c}^{E}\right]+(1-\pi)\left[\frac{c^{* L}-\hat{c}^{L}}{R}\right]=\left(q_{1}^{\max }-q_{1}^{N B}\right) B_{0}^{B}-\psi d .
$$

Using $\omega=u^{\prime}\left(c^{* E}\right)=R u^{\prime}\left(c^{* L}\right)$, the first term in A.52 becomes

$$
\pi\left[u\left(c^{* E}\right)-u\left(\hat{c}^{E}\right)\right]+(1-\pi)\left[u\left(c^{* L}\right)-u\left(\hat{c}^{L}\right)\right]-u^{\prime}\left(c^{* E}\right)\left(\pi\left[c^{* E}-\hat{c}^{E}\right]+(1-\pi)\left[\frac{c^{* L}-\hat{c}^{L}}{R}\right]\right)
$$

Due to the presence of deadweight losses from bank failure $(\psi d)$ and by the strictly concavity of $u(\cdot)$ this term is positive although it is smaller compared to A.45 because the fact that the bank had issued some equity makes the consumption allocations under no bailout better compared to the one in Proposition 2. This term represents the net gain to the debt buyback ignoring its impact on debt fragility. The buyback redistributes between depositors and investors in a way that restores the bank to solvency and avoids the deadweight bankruptcy costs. It also removes the risks faced by depositors due to strategic uncertainty in the debt market. This term is larger, the larger the costs of disrupting intermediation $\psi$.

The second term represents the additional costs of the debt buyback in terms of higher bankruptcy costs. It is proportional to the change in expected bankruptcy costs due to the bailout:

$$
\left(p^{P B}-1\right) \gamma<0
$$

and clearly negative due to higher probability of sovereign default under the bailout. It is clear that when $\psi$ is sufficiently large and $\gamma$ is sufficiently small, $\Delta>0$.

If, as in the second part of the proposition, $\gamma$ is sufficiently large and $\psi$ is sufficiently small, then, a full bailout will not occur, i.e. $\Delta<0$.

If markets clear at the presumed prices, then these are two sufficient conditions for $\Delta>0$ and a sufficient condition for $\Delta<0$. Step 3 of the proof shows that markets clear at the conjectured prices.

\section{Step 3: Market Clearing}

We construct prices such that markets clear. All government debt is held by banks as they receive the benefits of the debt buyback. From Assumption 1, this is feasible because bank deposits are larger than the government debt stock at the initial date.

When the bank knows it will receive a buyback price of $q_{1}^{\max }$ in the event of pessimism at the middle date and when it knows that the consumption allocations of depositors are independent of the sunspot (due to the combination of equity issuance and government bailout assistance), the bank is risk-neutral in its pricing of the bond. Let $\nu$ denote the probability of optimism. Hence at

$$
q_{0}=\nu \frac{1}{R}+(1-\nu) q_{1}^{\max }
$$

as assumed in the construction of the equilibrium, banks are indifferent between illiquid investment and the holding of government debt to finance the consumption of late households. Since $q_{1}^{\max }>q_{1}^{B B}$ 
(above market price buybacks), the price (A.55 is above what investors are prepared to pay for government debt. Hence banks hold the entire stock of government debt in period 0 and investors hold all the debt after period 1 trades.

Period 1 government debt prices are $q_{1}\left(s^{o}\right)=\frac{1}{R}$ and $q_{1}\left(s^{p}\right)=\frac{p^{P B}}{R}$ where $p^{P B}<1$ is the probability of repayment under bailout given by (A.49).

From the preferences of the investors, they are willing to lend as much as demanded in the interbank market if $r^{b}=R$. Thus this market will clear at that price with and without government debt buyback.

\subsubsection{Proof of Proposition 4}

Proposition 4. When banks expect no bailout, they fully insure their depositors by issuing equity. The first best banking contract is offered. The government does not need to bail out banks and therefore strategic uncertainty in the debt market disappears.

Proof. Let $q_{1}\left(s^{o}\right)$ be the price of government debt under optimism and $q_{1}\left(s^{p}\right)$ be the price of government debt under pessimism, with $q_{1}\left(s^{o}\right)>q_{1}\left(s^{p}\right)$ in the

The proof argues that there exists equity infusion $x_{0}$ such that (i) the contract with equity fully insulates depositors from risks and supports the first best allocation despite stochastic government debt prices and (ii) investors receive their required rate of return from the equity investment. We first determine the level of equity investment needed to support the first best contract, $\left(c^{* E}, c^{* L}\right)$. We then argue that the return on this equity equals the outside option of the investors.

Let $x_{0}$ denote the period 0 investment of equity holders into the bank and let $e_{0}$ denote its market value. Because the first best contract delivers state-uncontingent allocations to consumers, we drop the dependence of consumption on the sunspot state or the government's default decision. In the first best contract, the expected net present value of promises to depositors equals the amount they deposit at the initial date:

$$
\pi c^{* E}+\frac{(1-\pi) c^{* L}}{R}=d
$$

To support the first best contract, the bank must have sufficient resources to meet the contractual commitment to early consumers regardless of the realized government debt price:

$$
\pi c^{* E}=q_{1}\left(s^{p}\right) B_{0}^{B}
$$

where $q_{1}\left(s^{p}\right)$ is the period 1 price of government debt under pessimism. In this state, the bank sells its entire bond holding in order to pay off early consumers. Promises to late consumers are met through the illiquid investment:

$$
(1-\pi) c^{* L}=R i_{0}
$$


The cash flow for dividend payments to shareholders is only generated in the optimistic state. The bank rolls over its bond not needed to fund the early consumers:

$$
\pi c^{* E}=q_{1}\left(s^{o}\right)\left(B_{0}^{B}-B_{1}^{B}\left(s^{o}\right)\right) .
$$

The rolled over bond holding is then used to pay dividends to shareholders at the final date:

$$
\delta_{2}\left(s^{o}\right)=B_{1}^{B}\left(s^{o}\right)
$$

Since there is no default under optimism, the payment to equity holders is not indexed by the government default decision. The value of the equity to the shareholder is the discounted expected value of this dividend:

$$
e_{0}=\frac{\nu B_{1}^{B}\left(s^{o}\right)}{R}
$$

For the equity investment to be undertaken in equilibrium it must be the case that this expected value equals the equity put into the bank by the investor, i.e. $x_{0}=e_{0}$. Substituting A.56), A.57) and A.58 into A.2 yields $x_{0}=q_{0} B_{0}^{B}-\pi c^{* E}$. From this and from the definition of $q_{1}\left(s^{o}\right)$ and $q_{1}\left(s^{p}\right)$ the equity investment needed is:

$$
x_{0}=\nu \frac{(1-p)}{p} \pi c^{* E}
$$

Combining A.57) with A.59 wet:

$$
B_{1}^{B}\left(s^{o}\right)=R \frac{(1-p)}{p} \pi c^{* E}
$$

Hence

$$
e_{0}=\nu \frac{(1-p)}{p} \pi c^{* E}=x_{0}
$$

When the bank issues equity, it insulates its depositors from any uncertainty that affects bank portfolio returns. This implements the first best contract. This allocation satisfies the IC constraints, A.6.

While strategic uncertainty is still expected but no bailout is anticipated, banks have a strict incentive to issue equity. However, once banks issue equity, pessimism no longer requires a government bailout and is no longer an equilibrium. As a result, an individual bank is indifferent between issuing equity and not issuing in this equilibrium.

\subsubsection{Proof of Proposition 5}

Proposition 5. In a sunspot equilibrium with $G_{1}>0$ and no government bailout, if Assumption 4 holds, banks will fully insure their depositors by issuing equity. The first best banking contract is offered. 
Proof. The proof follows almost trivially from the proof of Proposition 4 where we demonstrated that issuing equity at the early date can insulate depositors from banking instability and can deliver the investors' required rate of return on equity. When $G_{1}>0$ and no government bailout and Assumption 4 holds, a pessimistic equilibrium will exist even when no bailout will be provided. Hence banks will strictly prefer to issue equity at the early date. Strategic uncertainty will exist in the debt market but this will not affect banks due to the equity cushions. The first best contract will be offered and a bank that does not issue will not attract any depositors. This allocation satisfies the IC constraints, A.6.

\subsubsection{Proof of Proposition 6}

Proposition 6. If $G_{1}=0$, a committed government will choose not to bailout the banks. In the SPNE, banks self-insure through equity issuance and provide the first best contract to households.

Proof. The proof has three steps: (i) characterizing the optimal banking contract, (ii) determining the government's bailout choice and (iii) checking market clearing.

\section{Step 1: Optimal Contract}

Under Assumption 2, sunspot equilibria exist even when the government does not bail out the banks and sovereign debt remains risky. Let $q_{1}\left(s^{o}\right)$ be the price of government debt under optimism and $q_{1}\left(s^{p}\right)$ be the price of government debt under pessimism, with $q_{1}\left(s^{o}\right)>q_{1}\left(s^{p}\right)$. Using Assumption 2, the outcome under optimism is the no default solution to the debt pricing equation. So $q_{1}\left(s^{o}\right)=q_{1}^{*}=\frac{1}{R} \cdot q_{1}\left(s^{p}\right)=\frac{p}{R}$ where $p<1$ is the probability of government repayment in the pessimistic equilibrium.

From Proposition 4 we know that, when the bank issues sufficient equity, depositors are fully insured against the uncertaintly in the government debt market and the first best banking contract can be offered. This allocation satisfies the IC constraints, A.6.

\section{Step 2: Government's Choice}

If the government commits to no bailout, then the first-best contract is provided by the banks and households bear no risk from variability of debt prices.

If, instead, the government commits to a bailout, it cannot improve upon the first-best allocation. The banks, as shown in the proof of Proposition 2, will continue to offer the first-best contract.

But the first-best allocation will not obtain. Under bailout, the government issues more debt. This will increase the probability of default directly and thus depress the valuation of government debt. Under pessimism, as seen in point 'PE' Figure 2, the outcome will be a lower value of government debt. The reduction in the value of debt implies the government must raise even more debt to finance bailouts.

The probability of default under a bailout becomes

$$
p^{B B}=1-F\left(\frac{B_{0}+T\left(\widehat{q}_{1}\right) / \widehat{q}_{1}}{\bar{A}}\right) .
$$


where $\widehat{q}_{1}$ denotes the value of government debt under a bailout in the pessimistic sunspot state, as in point 'PE' in Figure 2 .

When there is no bailout and no government spending, Assumption 1 guarrantees that the probability of repayment is unity. It is clear that the probability of repayment with bailouts $\left(p^{B B}\right)$ is smaller than unity for two reasons. First, under bailout, the government issues more debt as $T\left(\widehat{q}_{1}\right) \geq 0$. Second, $\widehat{q}_{1}<q_{1}\left(s^{p}\right)$, as seen in Figure 2. Hence the expected default cost, due to $\gamma>0$, is higher under a bailout.

\section{Step 3: Market Clearing}

The construction of equilibrium prices such that markets clear parallels that in the proof of Proposition 1 .

\subsubsection{Proof of Proposition 7}

\section{Proposition 7. If Condition 1 holds and}

1. either (i) the default cost, $\gamma$, is sufficiently small or (ii) the cost of resolving the banking system, $\psi$, is sufficiently large, there will exist a SPNE with a government long term debt buyback at a price of $q_{1}^{T}=\frac{1}{R}$ in the pessimistic sunspot state. The first best banking contract is offered to households supported by a bailout in the pessimistic state. No equity is issued by the bank.

2. the default cost, $\gamma$, is sufficiently large and the cost of resolving the banking system, $\psi$, is sufficiently small, there will not exist a SPNE with a government long term debt buyback at a price of $q_{1}^{T}=\frac{1}{R}$ in the pessimistic sunspot state.

Proof. The proof has three steps: (i) characterizing the optimal banking contract, (ii) determining the government's bailout choice and (iii) checking market clearing.

\section{Step 1: Optimal Contract}

First of all, we modify the banking contract to take into account the presence of short-term (1-period) and long-term (2 period) debt issued by the government at date 1 . We denote the bank's purchases of short and long term debt by $B_{0}^{1}$ and $B_{0}^{2}$ respectively. The prices of the two types of debt at date 0 are $q_{0}^{1}$ and $q_{0}^{2}$. The bank solves:

$$
\max _{i_{0}, B_{0}^{1}, B_{0}^{2}, x_{0}, c^{E}(s), c^{L}\left(s, \mathbb{1}_{G}\right), \delta_{2}\left(s, \mathbb{1}_{G}\right), l_{1}(s), B_{1}(s), L_{1}(s)} E\left[\pi u\left(c^{E}(s)\right)+(1-\pi) u\left(c^{L}\left(s, \mathbb{1}_{G}\right)\right)\right]
$$

such that

$$
\begin{gathered}
i_{0}+q_{0}^{1} B_{0}^{1}+q_{0}^{2} B_{0}^{2} \leq d+x_{0} \\
\pi c^{E}(s) \leq q_{1}(s)\left(B_{0}^{2}-B_{1}(s)\right)+B_{0}^{1}+\varepsilon l_{1}(s)-L_{1}(s)+T\left(q_{1}(s), B_{0}^{2}\right), \forall s \\
(1-\pi) c^{L}\left(s, \mathbb{1}_{G}\right) \leq\left(1-\mathbb{1}_{G}\right) B_{1}(s)+R\left(i_{0}-l_{1}(s)\right)-\delta_{2}\left(s, \mathbb{1}_{G}\right)-r^{b} L_{1}(s), \forall s
\end{gathered}
$$




$$
\begin{gathered}
E \delta_{2}\left(s, \mathbb{1}_{G}\right) \geq R x_{0} \\
E u\left(c^{L}\left(s, \mathbb{1}_{G}\right)\right) \geq u\left(\beta c^{E}(s)\right) ; E u\left(c^{E}(s)\right) \geq u\left(\beta c^{L}\left(s, \mathbb{1}_{G}\right)\right) \forall s
\end{gathered}
$$

$B_{1}(s)$ denotes the bank's purchases of one period debt in the middle period. The market price of 1-period debt in the middle date is $q_{1}(s)$.

To construct an equilibrium, suppose the banks anticipate a bailout of their long term debt holdings by the government in the event of pessimism. The banking contract with expected bailouts solves A.1 with the resource constraint for early consumers in the pessimistic state modified to reflect the government debt buyback program:

$$
\pi c^{E}\left(s^{p}\right) \leq \frac{1}{R}\left(B_{0}^{2}-B_{1}\left(s^{p}\right)\right)+B_{0}^{1}+\varepsilon l_{1}\left(s^{p}\right)-L_{1}\left(s^{p}\right)
$$

Here the government buys long-term (2 period) government bonds $B_{0}^{2}$ from the banks at the optimistic price of $q_{1}\left(s^{p}\right)=\frac{1}{R}$, making the return on long term government bonds independent of the sunspot. This is the form of anticipated government support in the pessimistic sunspot state. The government also repays the one period debt held by banks $B_{0}^{1}$.

The government debt support at $\frac{1}{R}$ implies that the contract between the bank and the households is immune from the sunspot. With the prices of short and long term debt at, respectively, $q_{0}^{1}=1$ and $q_{0}^{2}=\frac{1}{R}$, verified below, the bank problem is identical to that solved in the optimistic equilibrium, characterized in Proposition 1. Hence the banking contract is the first best one, $\left(c^{* E}, c^{* L}\right)$, which, as noted above, is incentive compatible.

Given that the households are insured through the government buyback, there is no gain to supplying equity to the bank. Hence $x_{0}=0$.

\section{Step 2: Government's Choice}

The proof here follows exactly the same logic as in Proposition 2, As long as the cost of having an insolvent banking system (determined by the parameter $\psi$ ) is greater than the increase in the expected default costs due to the higher government debt, the government will choose to bail out the banking system in the event of pessimism in the middle date. This happens when $\psi$ is large and $\gamma$ is small.

\section{Step 3: Market Clearing}

We construct prices such that markets clear. All long term government debt is held by banks as they receive the benefits of the debt buyback. From Assumption 1, this is feasible because bank deposits are larger than the government debt stock at the initial date of which long term government debt is a subset.

At $q_{0}^{2}=\frac{1}{R}$, as assumed in the construction of the equilibrium, banks are indifferent between illiquid investment and the holding of long term government debt to finance the consumption of late households. The banks are the marginal holders of the long term government debt in period 0. Along the equilibrium path, banks sell all the risky long term debt to investors at date 1 and do not buy any newly issued short term debt. In other words $B_{1}=0$. 
Period 1 prices are $q_{1}\left(s^{o}\right)=\frac{1}{R}$ and $q_{1}\left(s^{p}\right)=\frac{p^{B B}}{R}$ where $p^{B B}<1$ is the probability of repayment under bailout given by (A.41).

From the preferences of the investors, they are willing to lend as much as demanded in the interbank market if $r^{b}=R$. Also when $q_{0}^{1}=1$, investors and banks are willing to hold the short term debt supplied by the government at the early date. Since we are focusing on an equilibrium in which there is no government default in period 1, this date is safe and carries no bailouts. Hence both banks and investors would be willing to hold it at the conjectured market prices.

Thus all markets will clear.

\subsubsection{Proof of Proposition 8}

Proposition 8. There is no SPNE with bank runs.

Proof. (i) Suppose that Proposition 3 does not hold and a bailout is not desirable because $\gamma$ is large and/or $\psi$ is small. Then banks will issue equity thus achieving the run proof allocation. To see how this works, consider the Diamond-Dybvig case where $\varepsilon=1$. The consumption allocation is runs proof when it has enough liquid assets to pay out the early consumers' allocation to all depositors:

$$
c^{* E}<q_{1} b_{0}+i_{0}
$$

The date 0 bank balance sheet is given by

$$
x_{0}+d=q_{0} b_{0}+i_{0}
$$

where $x_{0}$ is the amount of equity bought by investors and $d$ is the total quantity of deposits. From Assumption 2 we know that, in the absence of bailouts, we are in the optimistic equilibrium where $q_{0}=q_{1}=R^{-1}$. This means that the bank needs to issue equity equal to

$$
x_{0}=c^{* E}-d
$$

in order to avoid runs. From Proposition 6 we know that when the government does not bailout the banks, they self insure through equity issuance. Hence they will issue equity $x_{0}=c^{* E}-d$ and no bank run will exist

(ii) Suppose Condition 1 holds and a full bailout is feasible in the event of pessimism. We know from Proposition 2 that, when $\gamma$ is sufficiently small and $\psi$ is sufficiently large the government will bail banks out fully when they experience losses on their sovereign debt holdings. In such a scenario no bank run will exist.

(iii) Suppose Condition 2 holds and a full bailout is not feasible in the event of pessimism. We know from Proposition 3 that the SPNE features partial bailout by the government and partial equity issuance by the banks. When $\gamma$ is sufficiently small and $\psi$ is sufficiently large the government will bail banks out partially (up to the extent that is feasible) when they experience losses on their 
sovereign debt holdings provided that this avoids bank failure and avoids incurring the cost of bank failure $\psi$. Recongnising this, banks will issue just enough equity so that the partial bailout saves them and insures depositors fully. In such a scenario no bank run will exist. 


\section{References}

Acharya, V. V., I. Drechsler, and P. Schnabl (2014): "A pyrrhic victory?-bank bailouts and sovereign credit risk," Journal of Finance.

Admati, A., And M. Hellwig (2013): Bankers' New Clothes: What is Wrong with Banking and What to do about it? Princeton University Press.

Battistini, N., M. Pagano, and S. Simonelli (2014): "Systemic Risk, Sovereign Yields and Bank Exposures in the Euro Crisis," Economic Policy.

Bennett, R., And H. UnAL (2014): "Understanding the components of bank failure resolution costs," FDIC CFR Working Paper.

Bolton, P., and O. Jeanne (2011): "Sovereign Default Risk and Bank Fragility in Financial Integrated Economies," IMF Economic Review, 59(2), 162-194.

Broner, F., A. Erce, A. Martin, and J. Ventura (2014): "Sovereign Debt Markets in Turbulent Times: Creditor Discrimination and Crowding-Out Effects," Journal of Monetary Economics.

Calvo, G. (1988): "Servicing the public debt: The role of expectations," The American Economic Review, pp. 647-661.

Carlsson, H., And E. VAn Damme (1993): "Global games and equilibrium selection," Econometrica.

Cole, H., And T. Kehoe (2000): "Self-Fulfilling Debt Crises," Review of Economic Studies, $67(1), 91-116$.

Cooper, R. (2012): "Fragile Debt and the Credible Sharing of Strategic Uncertainty," NBER Working Paper \# 18377.

CoOper, R., And H. KempF (2015): "Deposit insurance and bank liquidation without commitment: Can we sleep well?," Economic Theory, pp. 1-28.

Cooper, R., H. Kempf, And D. Peled (2008): "Is it is or it is ain't my obligation? Regional Debt in a Fiscal Federation," International Economic Review, 49, 1469-1504.

Corsetti, G., And L. Dedola (2012): "Fiscal Crises, Confidence and Default A Bare-bones Model with Lessons for the Euro Area," mimeo.

De Grauwe, P., And Y. Ji (2012): "Mispricing of Sovereign Risk and Multiple Equilibria in the Eurozone," mimeo. 
Diamond, D., And P. Dybvig (1983): "Bank Runs, Deposit Insurance and Liquidity," Journal of Political Economy, 91, 401-19.

Eaton, J., And M. Gersowitz (1981): "Debt with Potential Repudiation: Theoretical and Empirical Analysis," Review of Economic Studies, 42(2), 289-309.

Ennis, H., And T. Keister (2009): "Bank runs and institutions: the perils of intervention," The American Economic Review, 99(4), 1588-1607.

FArhi, E., And J. Tirole (2014): "Deadly Embrace: Sovereign and Financial Balance Sheets Doom Loops," mimeo.

Gennaioli, N., A. Martin, and S. Rossi (2013): "Sovereign Default, Domestic Banks and Financial Institutions," Journal of Finance.

(2014): "Banks, Government Bonds, and Default: What do the Data Say?," mimeo.

Guo, J., And S. G. Harrison (2008): "Useful Government Spending and Macroeconomic (In)stability under Balanced-Budget Rules," Journal of Public Economic Theory, 10(3), 383397.

Hannoun, H. (2011): "Financial crises: the role of deposit insurance," Presentation, Bank for International Settlements.

Leonello, A. (2014): "Government Guarantees and the Two-Way Feedback between Banking and Sovereign Debt Crises," mimeo.

Livshits, I., And K. Schoors (2012): "Sovereign default and banking," mimeo.

Lucas, A., B. SchwaAb, and X. Zhang (2014): "Conditional Euro Area Sovereign Default Risk," Journal of Business and Economic Statistics.

(2017): "The passthrough of sovereign risk," Journal of Political Economy.

Mendicino, C., K. Nikolov, and J. Suarez (2016): "Equity versus bail-in debt in banking: an agency perspective," mimeo.

Morris, S., AND H. SHIn (1998): "Unique equilibrium in a model of self-fulfillig currency attacks," American Economic Review.

Ongena, S., A. Popov, and N. Van Horen (2015): "Is there moral suasion in banking?," mimeo.

Pagano, M. (2014): "Lessons from the European Financial Crisis," Centre for Studies in Economics and Finance Working Paper No. 370. 
Popov, A., And N. VAn Horen (2015): "Exporting Sovereign Stress: Evidence from Syndicated Bank Lending During the Euro Area Sovereign Debt Crisis," Review of Finance.

Roch, F., AND H. Uhlig (2012): "The Dynamics of Sovereign Debt Crises and Bailouts," http://www.ecb.europa.eu/events/conferences/shared/pdf/researchforum7/ Uhlig_Harald.pdf?090aa93a65cfbc331785bf7f09c79737, mimeo.

Uhlig, H. (2013): "Sovereign Default and Banks in a Monetary Union," NBER Working Paper \#19343.

VIVES, X. (2014): "Strategic Complementarity, Fragility and Regulation," Review of Financial $\underline{\text { Studies. }}$ 